\title{
CFD Method for Predicting Annular Pressure Losses and Cuttings Concentration in Eccentric Horizontal Wells
}

\author{
Titus N. Ofei, ${ }^{1}$ Sonny Irawan, ${ }^{1}$ and William Pao ${ }^{2}$ \\ ${ }^{1}$ Petroleum Engineering Department, Universiti Teknologi PETRONAS, Bandar Seri Iskandar, 31750 Tronoh, Malaysia \\ ${ }^{2}$ Mechanical Engineering Department, Universiti Teknologi PETRONAS, Bandar Seri Iskandar, 31750 Tronoh, Malaysia \\ Correspondence should be addressed to Titus N. Ofei; titusofei@hotmail.com
}

Received 28 December 2013; Accepted 10 March 2014; Published 10 April 2014

Academic Editor: Markus Kraft

Copyright (c) 2014 Titus N. Ofei et al. This is an open access article distributed under the Creative Commons Attribution License, which permits unrestricted use, distribution, and reproduction in any medium, provided the original work is properly cited.

\begin{abstract}
In oil and gas drilling operations, predictions of pressure losses and cuttings concentration in the annulus are very complex due to the combination of interacting drilling parameters. Past studies have proposed many empirical correlations to estimate pressure losses and cuttings concentration. However, these developed correlations are limited to their experimental data range and setup, and hence, they cannot be applicable to all cases. CFD methods have the advantages of handling complex multiphase flow problems, as well as, an unlimited number of physical and operational conditions. The present study employs the inhomogeneous (EulerianEulerian) model to simulate a two-phase solid-fluid flow and predict pressure losses and cuttings concentration in eccentric horizontal annuli as a function of varying drilling parameters: fluid velocity, diameter ratio (ratio of inner pipe diameter to outer pipe diameter), inner pipe rotation speed, and fluid type. Experimental data for pressure losses and cuttings concentration from previous literature compared very well with simulation data, confirming the validity of the current model. The study shows how reliable CFD methods can replicate the actual, yet complex oil and gas drilling operations.
\end{abstract}

\section{Introduction}

Predictions of pressure losses and cuttings concentration in annular wells are strongly affected by varying drilling parameters such as fluid velocity, fluid properties (density, viscosity), cuttings size and density, hole-pipe eccentricity, drill pipe rotation, and annular diameter ratios. There are few attempts made by some investigators to estimate pressure losses and cuttings concentration in annular geometries with and without drill pipe rotation by employing either experimental or numerical approaches.

Among the first authors to conduct extensive experimental study on cuttings transport at varying angles of inclinations is Tomren et al. [1]. The authors studied the effects of fluid velocity, fluid rheological properties, pipe-hole eccentricity, drill pipe rotation, and flow regimes on cuttings concentration at steady state condition. They concluded that fluid velocity, hole inclination, and mud rheological properties were the major factors affecting mud carrying capacity. Becker and Azar [2] also investigated experimentally the effects of mud weight and annular diameter ratio on the performance of hole cleaning in inclined wellbores. The authors observed that variations in the drill pipe have minimum effect on particle concentration for the same fluid velocity. According to Adari et al. [3], the practical use of drilling factors in controlling cuttings transport is much dependent on their controllability in the field. It is believed that, cuttings transported in the annulus are not always affected by a single parameter, but a combination of parameters to ensure efficient hole cleaning [4]. Other studies have also confirmed that increase in fluid velocity results in a decrease in cuttings accumulation in the wellbore [5-7]. Ozbayoglu and Sorgun [8] also conducted cuttings transport experiment and developed empirical correlations for estimating pressure losses with the presence of cuttings and drill pipe rotation in horizontal and inclined wellbores. They observed that the influence of drill pipe rotation on pressure loss is more significant if fluid is more nonNewtonian. The annular test section has diameter ratio of 0.62 . Similar cuttings transport experiment study was carried out by Sorgun et al. [9] in horizontal and inclined annular geometry of diameter ratio of 0.62 . The authors observed 
that, the existence of cuttings in the system caused an increase in pressure loss due to a decrease in flow area inside the annular gap. Further observation was that, drill pipe rotation decreases the pressure loss significantly if the drill pipe is making orbital motion in eccentric annulus. Another experimental study was conducted [10] to analyse the effects of some "very difficult to identify" data on the estimation of total pressure loss and cuttings concentration in horizontal and inclined annulus. Results from this study indicate that drill pipe rotation does not have significant influence on pressure loss for constant rate of penetration (ROP) and fluid velocity. The annular test section has diameter ratio of 0.64 .

One of the pioneering works by Markatos et al. [11] modelled single phase Newtonian flow in nonuniform narrow annular gaps using finite difference technique. The velocity flow fields as well as static pressure were predicted in a twodimensional flow.

Han et al. [12] is among the first to conduct experimental and CFD studies on solid-fluid mixture flow in vertical and highly deviated slim hole annulus. They concluded that, annular pressure losses increase with mixture fluid velocity, annular angle of inclination, and drill pipe rotation speed. The annular test section has diameter ratio of 0.70 . Mokhtari et al. [13] employed CFD method to model the effects of eccentricity and flow behaviour index on annular pressure loss and velocity profile for varying diameter ratios from 0.30 to 0.90 . The authors, however, did not include cuttings in the annular mainstream. Recently, Ofei et al. [14] also employed CFD technique to analyse the influence of diameter ratio, fluid velocity, fluid type, fluid rheology, and drill pipe rotation speed on pressure loss in eccentric horizontal wellbore with the presence of cuttings.

The present study also utilises a CFD technique to examine the effects of fluid velocity, annular diameter ratio (ranging from 0.64 to 0.90 ), drill pipe rotation, and fluid type on the prediction of pressure loss and cuttings concentration for solid-fluid flow in eccentric horizontal wellbore. Contours of cuttings volume fraction, 3D cuttings velocity streamlines and radial cuttings velocity profiles are also presented to give further insight on cuttings transport. The new findings from this study would provide better understanding and guide in the selection of optimum drilling parameters in narrow annuli drilling such as casing drilling and slim holes.

\section{Materials and Methods}

Multiphase component of CFD software ANSYS-CFX 14.0 is adopted in this study. In ANSYS-CFX, a multiphase flow containing dispersed particles may be modelled using either Lagrangian Particle Tracking model or EulerianEulerian model. The inhomogeneous (Eulerian-Eulerian) model, sometimes called the two-fluid model, regards both continuous and dispersed phases as continuous media. In this study, the Eulerian-Eulerian model is preferred to the Lagrangian Particle Tracking model due to its ability to handle high solid volume fractions. Furthermore, it accounts for solid particle-particle interaction and includes turbulence automatically [15]. A drawback of this model is, however, that they need complex closure relations. The following continuity and momentum equations representing the two-phase flow model are described for the sake of brevity.

2.1. Continuity Equations. The fluid phase continuity equation assuming isothermal flow condition can be expressed as $[16,17]$

$$
\frac{\partial}{\partial t}\left(h_{l}\right)+\nabla\left(h_{l} U_{l}\right)=0
$$

Similarly, for a solid phase,

$$
\frac{\partial}{\partial t}\left(h_{s}\right)+\nabla\left(h_{s} U_{s}\right)=0
$$

where the solid and fluid phase volume fraction sum up as follows:

$$
k_{s}+k_{l}=1
$$

At steady state condition, $\partial / \partial t=0$.

2.2. Momentum Equations. The forces acting on each phase and interphase momentum transfer term that models the interaction between each phase are given below [16, 17].

For fluid phase,

$$
\rho_{l} k_{l}\left[\frac{\partial U_{l}}{\partial t}+U_{l} \cdot \nabla U_{l}\right]=-k_{l} \nabla p+k_{l} \nabla \cdot \overline{\bar{\tau}}_{l}+k_{l} \rho_{l} g-M .
$$

Similarly, for solid phase,

$$
\begin{aligned}
\rho_{s} h_{s} & {\left[\frac{\partial U_{s}}{\partial t}+U_{s} \cdot \nabla U_{s}\right] } \\
& =-h_{s} \nabla p+h_{s} \nabla \cdot \overline{\bar{\tau}}_{l}+\nabla \cdot \overline{\bar{\tau}}_{s}-\nabla P_{s}+h_{s} \rho_{s} g+M .
\end{aligned}
$$

At steady state condition, $\partial / \partial t=0$.

\subsection{Other Closure Models}

2.3.1. Interphase Drag Force Model. For spherical particles, the drag force per unit volume is given as

$$
M_{d}=\frac{3 C_{D}}{4 d_{s}} k_{s} \rho_{l}\left|U_{s}-U_{l}\right|\left(U_{s}-U_{l}\right) .
$$

For densely distributed solid particles, where the solid volume fraction $k_{s}<0.2$, the Wen and Yu [18] drag coefficient model may be utilised. This model is modified and implemented in ANSYS-CFX to ensure the correct limiting behaviour in the inertial regime as

$$
C_{D}=k_{l}^{-1.65} \max \left[\frac{24}{N_{\mathrm{Re}_{p}}^{\prime}}\left(1+0.15 N_{\mathrm{Re}_{p}}^{\prime 0.687}\right), 0.44\right] \text {, }
$$

where $N_{\mathrm{Re}_{p}}^{\prime}=\ell_{l} N_{\mathrm{Re}_{p}}$ and $N_{\mathrm{Re}_{p}}=\rho_{l}\left|U_{l}-U_{s}\right| d_{s} / \mu_{l}$. 
For large solid volume fraction, $k_{s}>0.2$, the Gidaspow drag model may be used with the interphase drag force per unit volume defined as [19]

$$
M_{D}=\frac{150\left(1-k_{l}\right)^{2} \mu_{l}}{k_{l} d_{s}^{2}}+\frac{7}{4} \frac{\left(1-k_{l}\right) \rho_{l}\left|U_{l}-U_{s}\right|}{d_{s}} .
$$

In this study, both Wen and Yu and Gidaspow drag models were employed depending on the computed solid volume fraction. An approximate method for computing the solid volume fraction is presented in (18).

2.3.2. Lift Force Model. For spherical solid particles, ANSYSCFX employs the Saffman and Mei lift force model as

$$
M_{L}=\frac{3}{2 \pi} \frac{\sqrt{\nu_{l}}}{d_{s} \sqrt{\left|\nabla \times U_{l}\right|}} C_{L}^{\prime} \hbar_{s} \rho_{l}\left(U_{s}-U_{l}\right) \times\left(\nabla \times U_{l}+2 \Omega\right) .
$$

Saffman [20, 21] correlated the lift force for low Reynolds number past a spherical solid particle where $C_{L}^{\prime}=6.46$, and $0 \leq N_{\mathrm{Re}_{p}} \leq N_{\mathrm{Re}_{\omega}} \leq 1$. For higher range of solid particle Reynolds number, Saffman's correlation was generalised by Mei and Klausner [22] as follows:

$$
C_{L}^{\prime}= \begin{cases}6.46 \cdot f\left(N_{\mathrm{Re}_{p}}, N_{\mathrm{Re}_{\omega}}\right) & \text { for: } N_{\mathrm{Re}_{p}}<40 \\ 6.46 \cdot 0.0524 \cdot\left(\beta N_{\mathrm{Re}_{p}}\right)^{1 / 2} & \text { for: } 40<N_{\mathrm{Re}_{p}}<100\end{cases}
$$

where $\beta=0.5\left(N_{\operatorname{Re}_{\omega}} / N_{\operatorname{Re}_{p}}\right)$,

$$
f\left(N_{\operatorname{Re}_{p}}, N_{\operatorname{Re}_{\omega}}\right)=\left(1-0.3314 \beta^{0.5}\right) \cdot e^{-0.1 N_{\operatorname{Re}_{p}}}+0.3314 \beta^{0.5},
$$

and $N_{\mathrm{Re}_{\omega}}=\rho_{l} \omega_{l} d_{s}^{2} / \mu_{l}, \omega_{l}=\left|\nabla \times U_{l}\right|$.

2.3.3. Turbulence $k-\varepsilon$ Model in Multiphase Flow. The $k-\varepsilon$ turbulence model offers a good compromise in terms of accuracy and robustness for general purpose simulations. It is a semiempirical model based on transport equation for the estimation of turbulent length scale and velocity scale from the turbulent kinetic energy $(k)$ and dissipation rate $(\varepsilon)$ [23]. In multiphase flow, the transport equations for $k$ and $\varepsilon$ are phase dependent and assume a similar form to the singlephase transport equations, respectively, as

$$
\begin{gathered}
\frac{\partial}{\partial t}\left(C_{\alpha} \rho_{\alpha} k_{\alpha}\right)+\nabla \cdot\left(C_{\alpha}\left(\rho_{\alpha} U_{\alpha} k_{\alpha}-\left(\mu+\frac{\mu_{t \alpha}}{\sigma_{k}}\right) \nabla k_{\alpha}\right)\right) \\
=C_{\alpha}\left(P_{\alpha}-\rho_{\alpha} \varepsilon_{\alpha}\right)+T_{\alpha \beta}^{(k)}, \\
\frac{\partial}{\partial t}\left(C_{\alpha} \rho_{\alpha} \varepsilon_{\alpha}\right)+\nabla \cdot\left(C_{\alpha} \rho_{\alpha} U_{\alpha} \varepsilon_{\alpha}-\left(\mu+\frac{\mu_{t \alpha}}{\sigma_{\varepsilon}}\right) \nabla \varepsilon_{\alpha}\right) \\
=C_{\alpha} \frac{\varepsilon_{\alpha}}{k_{\alpha}}\left(C_{\varepsilon 1} P_{\alpha}-C_{\varepsilon 2} \rho_{\alpha} \varepsilon_{\alpha}\right)+T_{\alpha \beta}^{(\varepsilon)} .
\end{gathered}
$$

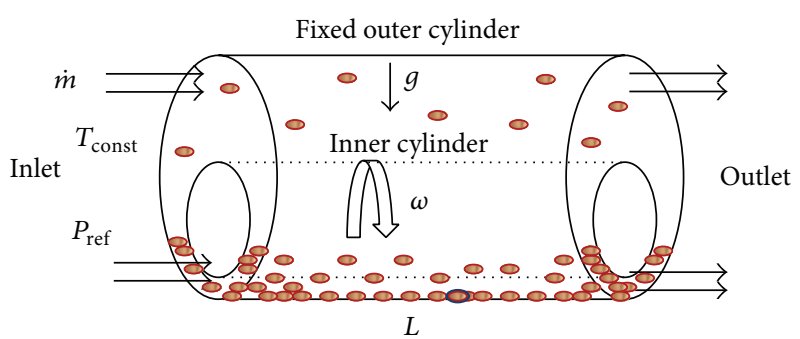

FIgure 1: Physical model for solid-fluid flow.

Diffusion of momentum in phase $\alpha$ is governed by an effective viscosity as

$$
\mu_{\mathrm{eff}}=\mu+\mu_{t \alpha}
$$

The $k-\varepsilon$ model assumes that the turbulence viscosity is linked to the turbulence kinetic energy and dissipation by the following relation:

$$
\mu_{t \alpha}=C_{\mu} \rho_{\alpha} \frac{k_{\alpha}^{2}}{\varepsilon_{\alpha}}
$$

The governing sets of partial differential equations were discretized using finite volume technique. The discretized equations together with initial and boundary conditions are solved iteratively for each control volume of pressure drop and cuttings concentration using ANSYS CFX 14.0 solver.

2.4. Physical Model and Carrier Fluid. Two-phase solid-fluid flow in eccentric horizontal annulus with stationary outer pipe and rotating inner pipe is presented. The inner pipe represents the actual drill pipe while the outer pipe represents the hole. Four annular 3D geometries are modelled with diameter ratios $\kappa=0.64,0.70,0.80$ and 0.90 using ANSYS Workbench.

In order to eliminate end effects and ensure fully developed flow, the length of the annular pipe must be longer than the hydrodynamic entrance length. For a single phase Newtonian fluid flowing in a pipe, the hydrodynamic length is presented by Shook and Roco [24] as

$$
L_{h}=0.062 N_{\operatorname{Re}}(D) \text {. }
$$

However, for a two-phase flow in annular gap with a nonNewtonian fluid, such expression as in (16) does not yet exist in literature. As a rule of thumb, the authors have adopted (16) by replacing the pipe diameter $D$ with a hydraulic diameter $D_{h}=D_{2}-D_{1}$. It should be noted that a much longer annular length would only result in a computationally expensive CFD simulation. Figure 1 shows the physical model for solid-fluid flow. The fluid is considered incompressible, steady state, and isothermal. The rheology of the fluid is described by both Newtonian (water) and Power-Law model. The apparent viscosity for Power-Law model is given as

$$
\mu_{a}=K \dot{\gamma}^{n-1}
$$




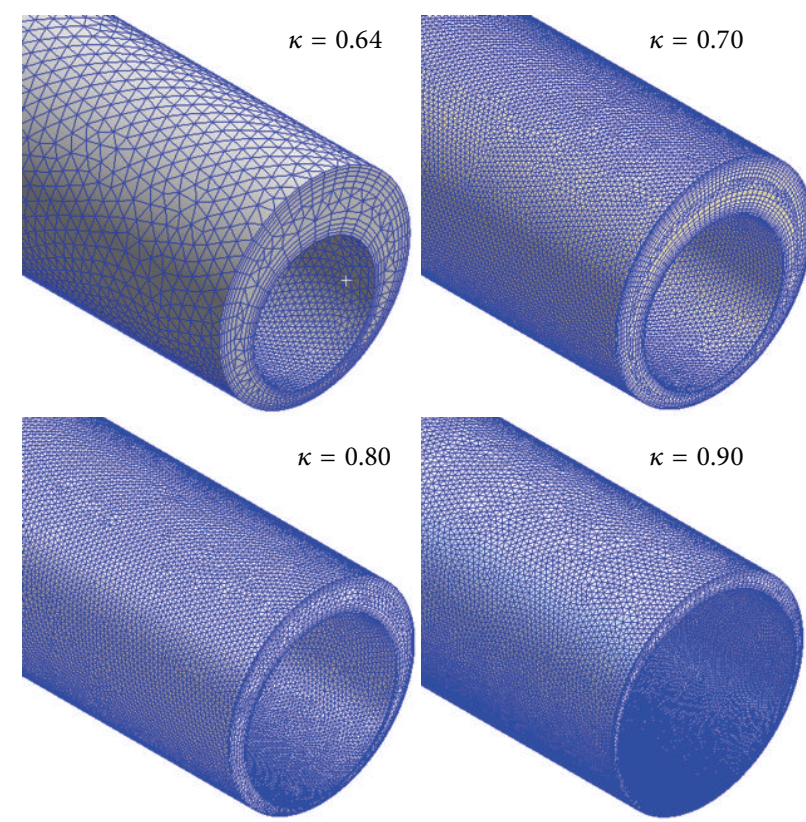

Figure 2: 3D section of meshed annular geometry.

where $K$ is consistency index, $\dot{\gamma}$ is shear rate, and $n$ is flow behaviour index. For $n=1$, (17) reduces to Newtonian model, $n<1$, fluid is shear thinning, and $n>1$, fluid is shear thickening. In this study, $0.3<n \leq 1$.

2.5. Boundary Conditions and Meshing. A mixture mass flow rate boundary condition was specified at the inlet while zero gauge pressure specified at the outlet. No-slip boundary conditions were imposed on both inner and outer pipe walls for both fluid and particles. The 3D annular geometries were meshed into unstructured tetrahedral grids of approximately $0.66-2.15 \times 10^{6}$ elements. Inflation layers were created near the walls covering about $20 \%$ of the inner and outer radii for resolving the mesh in the near-wall region as well as accurately capturing the flow effects in that region. Figure 2 shows the $3 \mathrm{D}$ section of the meshed annular geometries.

2.6. Grid Independence Study. To optimise the mesh sizes until results were insignificantly dependent on mesh size, grid independence study was conducted for all diameter ratios. The carrier fluid used is water flowing at a velocity of $2.743 \mathrm{~m} / \mathrm{s}$ and the inner pipe rotation speed is $80 \mathrm{rpm}$. The cuttings feed concentration which gives an idea of the amount of particles in motion that are introduced to the annular space. This is computed as a function of area of bit, fluid velocity, and rate of penetration (ROP) as [6]

$$
C_{\mathrm{cf}}=\frac{(\mathrm{ROP}) A_{\mathrm{bit}}}{R_{T} \mathrm{Q}}
$$

where $R_{T}$ is defined as the ratio of the particle transport velocity to the average annular fluid velocity. For the purpose of this study, $R_{T}$ is taken as 0.5 based on experimental findings [9]. Figures $3(\mathrm{a})$ to $3(\mathrm{~d})$ show the variation of pressure losses as a function of element sizes. In Figures 3 (a) and 3(b), element size of $0.003 \mathrm{~m}$ and below would result in insignificant changes in pressure losses; however, more computational time is required for elements sizes below $0.003 \mathrm{~m}$. In Figures 3(c) and 3(d), element size of $0.003 \mathrm{~m}$ and above also shows no significant changes in pressure losses. An optimum element size of $0.003 \mathrm{~m}$ is chosen for all diameter ratios resulting in approximately $0.66-2.15 \times 10^{6}$ number of elements with increasing diameter ratio from 0.64 to 0.90 . The CPU time recorded in this study ranges between $7.2 \times$ $10^{3} \mathrm{~s}$ to $5.4 \times 10^{4} \mathrm{~s}$. The simulations were run on a computer with the following specifications: Windows 7 64-bit operating system, with 4 GB RAM, and Pentium Dual-Core processor at $2.3 \mathrm{GHz}$.

2.7. Simulation Model Validation. The simulation model setups were validated against experiment data available from previous studies. Pressure loss and cuttings concentration data for cuttings-water flow in a horizontal wellbore were adopted from Osgouei [25]. Also, pressure loss data using non-Newtonian fluid of $0.4 \%$ CMC solution for cuttings transport experiment were adopted from Han et al. [12]. Table 1 summarises the rheological properties and operating parameters for the experimental studies.

From Figure 4(a), the calculated pressure loss slightly overpredicted the experimental data by a mean percentage error of $0.84 \%$. Similarly, the calculated cuttings concentration data slightly overpredicted the experimental data by a mean percentage error of $12 \%$ as shown in Figure $4(\mathrm{~b})$. The total cuttings concentration, $C_{\mathrm{cT}}$, is defined as

$$
C_{\mathrm{cT}}=\frac{\text { Net volume occupied by particles }}{\text { Total volume of annlulus }} \times 100 \text {. }
$$

Moreover, Figure 4(c) shows the calculated pressure loss deviating slightly from the experimental data by a mean percentage error of $2.5 \%$. The analyses show a good agreement between calculated and experimental data confirming the validity of the current model setup.

2.8. Simulation Study. Table 2 summarises the simulation setup including fluid rheological properties and drilling parameters. The present study adopts the Eulerian-Eulerian model to simulate a two-phase solid-fluid flow in eccentric horizontal annuli. ANSYS-CFX solver, which is based on a finite volume method [26], is used to solve the continuity and momentum equations with the appropriate initial and boundary conditions. The solution is assumed to be converged when the root mean square (RMS) of the normalised residual error reached $10^{-4}$ for all simulations. Both Newtonian (water) and non-Newtonian (Power-Law model) fluids are used as carrier fluids. Variations in annular pressure losses and cuttings concentration as a function of fluid velocity, diameter ratio, inner pipe rotation speed, and fluid type are analysed and results are presented. In addition, contours of cuttings volume fraction and cuttings velocities, streamlines of cuttings velocities, as well as profiles of cuttings velocities are also presented. 


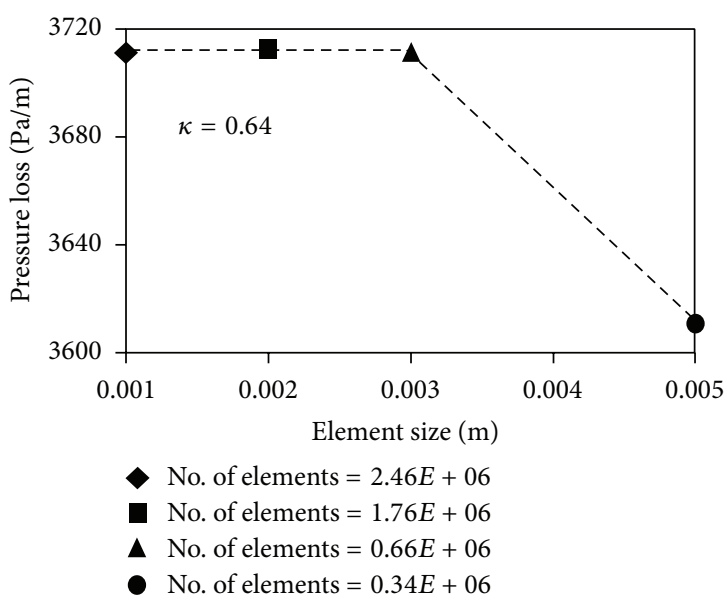

(a)

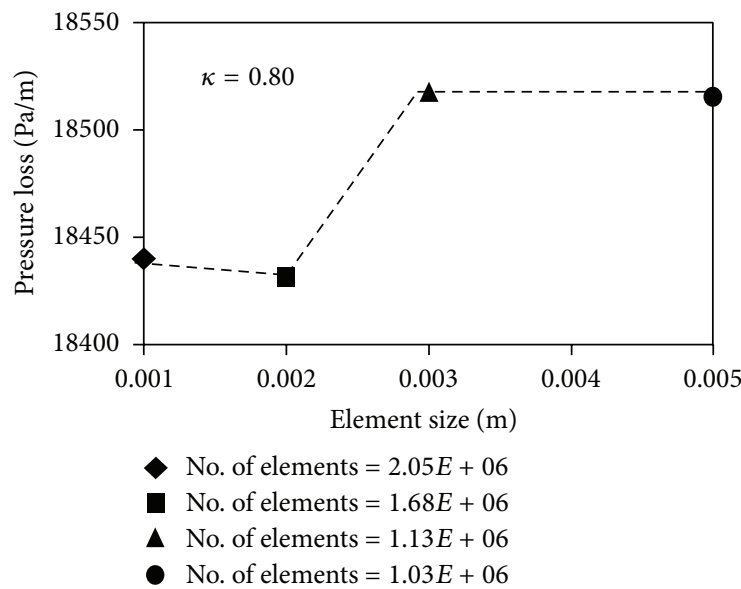

(c)

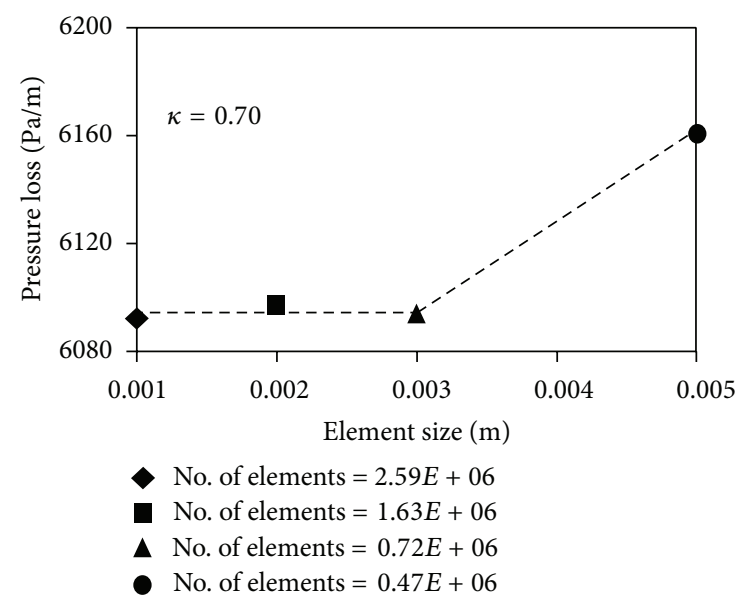

(b)

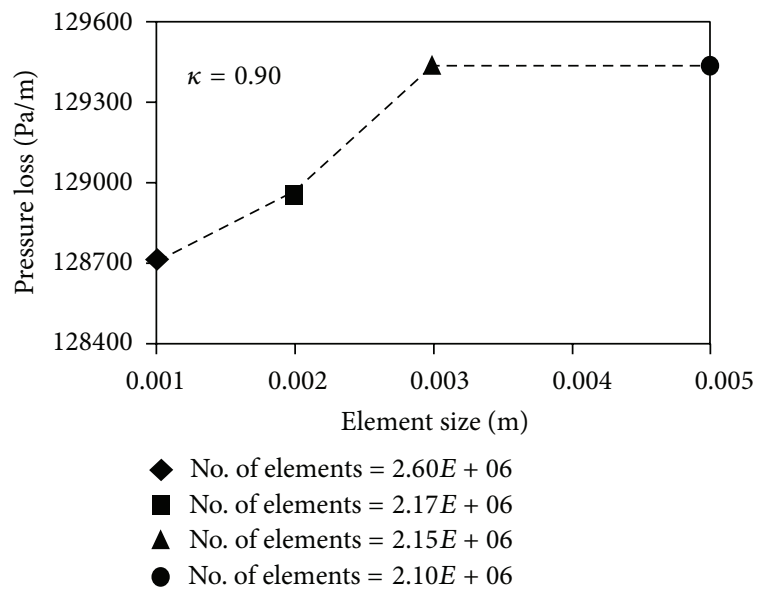

(d)

FIGURE 3: Grid independence study: (a) $\kappa=0.64$, (b) $\kappa=0.70$, (c) $\kappa=0.80$, (d) $\kappa=0.90$ at $80 \mathrm{rpm}$.

TABLE 1: Summary of experimental data from previous studies.

\begin{tabular}{lcccccccccc}
\hline $\begin{array}{l}\text { Experimental } \\
\text { data source }\end{array}$ & $\begin{array}{c}\text { Fluid density } \\
\left(\mathrm{kg} / \mathrm{m}^{3}\right)\end{array}$ & $n(-)$ & $K\left(\mathrm{~Pa} \mathrm{~s}^{n}\right)$ & $\begin{array}{c}\text { Pipe rotation } \\
(\mathrm{rpm})\end{array}$ & $\kappa\left(D_{1} / D_{2}\right)$ & $e(-)$ & $\begin{array}{c}\text { Fluid } \\
\text { velocity } \\
(\mathrm{m} / \mathrm{s})\end{array}$ & $\begin{array}{c}\text { Avg. } \\
\text { cuttings } \\
\text { size }(\mathrm{m})\end{array}$ & $\begin{array}{c}\text { Cuttings } \\
\text { density } \\
\left(\mathrm{kg} / \mathrm{m}^{3}\right)\end{array}$ & $\begin{array}{c}\mathrm{ROP} \\
(\mathrm{m} / \mathrm{s})\end{array}$ \\
\hline Osgouei [25] & 998.5 & 1.0 & 0.001 & 80 & 0.64 & 0.623 & $\begin{array}{c}1.524- \\
2.7432\end{array}$ & 0.00201 & 2761.4 & 0.00508 \\
Han et al. [12] & 998.5 & 0.75 & 0.048 & 0 & 0.70 & 0 & $\begin{array}{c}0.327- \\
0.654\end{array}$ & 0.001 & 2550 & 0.00526 \\
\hline
\end{tabular}

\section{Results and Discussion}

3.1. Effect of Fluid Velocity. Previous studies [1, 4] have revealed that fluid velocity is a dominant factor during cuttings transport. This phenomenon is also observed in this study. Figure 5 presents the variations in pressure loss and cuttings concentration as a function of increasing annular fluid velocity at constant diameter ratio and $80 \mathrm{rpm}$. Using both water and mud as carrier fluids, increasing fluid velocity significantly increases pressure losses, while a decrease in cuttings concentration occurs for each constant diameter ratio. This effect is however more pronounced for $\kappa=0.90$.
Figures 5(a)-5(d) depict these observations. For instance, when using mud as carrier fluid in Figure 5(c) and for $\kappa=$ 0.90 , annular pressure loss was dramatically increased by $97 \%$ when the flowing fluid velocity increased from $1.524 \mathrm{~m} / \mathrm{s}$ to $2.749 \mathrm{~m} / \mathrm{s}$. Similarly, as shown in Figure 5(d), the cuttings concentration decreased by $37 \%$ in the annulus as fluid velocity increased from $1.524 \mathrm{~m} / \mathrm{s}$ to $2.749 \mathrm{~m} / \mathrm{s}$ for $\kappa=$ 0.90. Another observation is that, in Figure 5(b), where the carrier fluid is water, there is almost no variation in cuttings concentration as fluid velocity increases for $\kappa=0.90$. This indicates that in extreme narrow annuli, lower fluid velocities are capable of transporting enough cuttings from the annulus, 


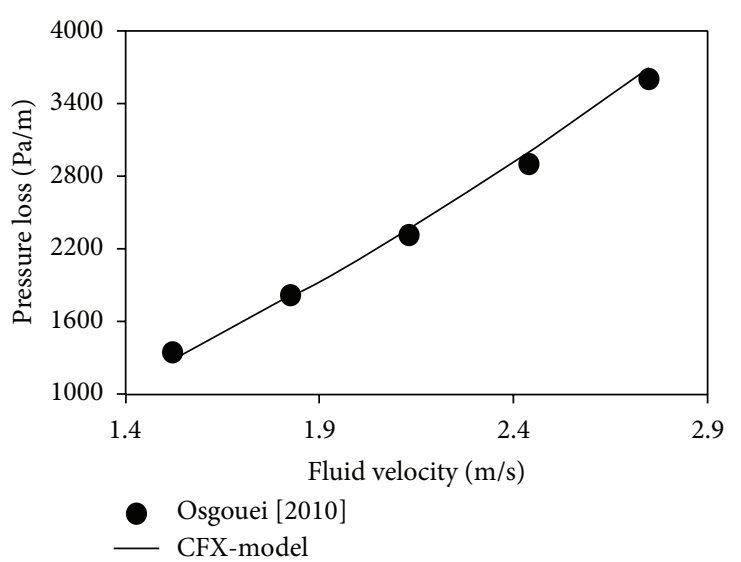

(a)

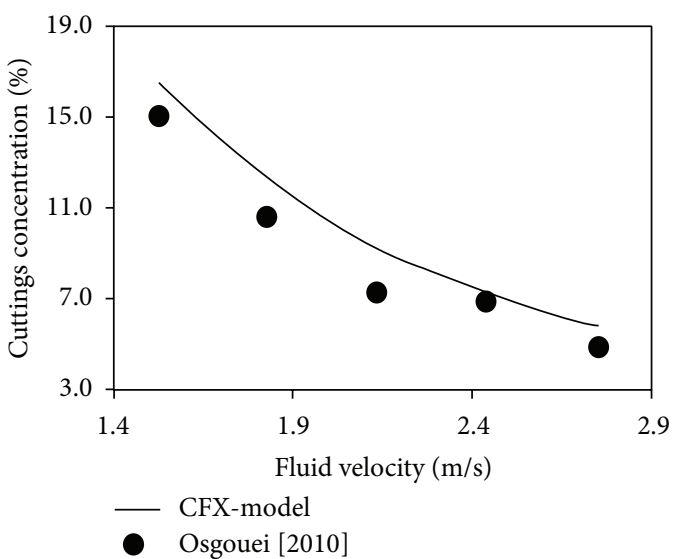

(b)

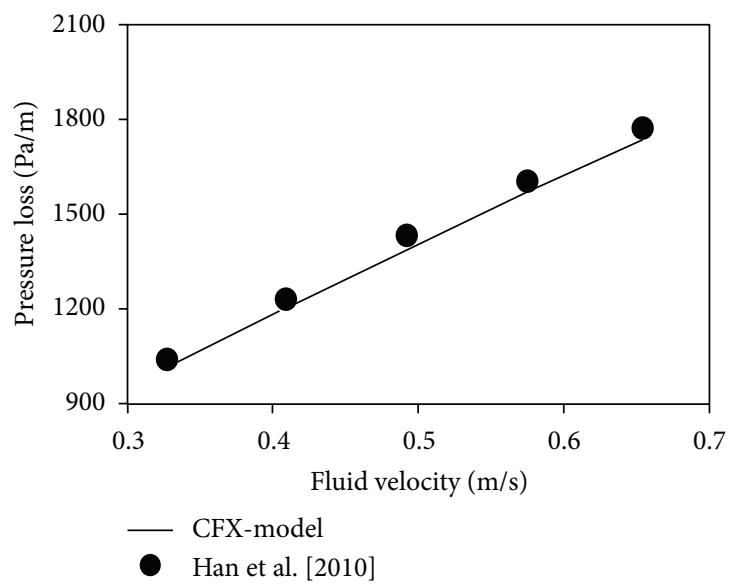

(c)

Figure 4: Experimental and simulation data comparison: (a) pressure loss data for cuttings-water flow, (b) cuttings concentration data for cuttings-water flow, (c) pressure loss data for cuttings- $0.4 \%$ CMC flow.

TABLE 2: Simulation data for cuttings fluid flow.

\begin{tabular}{lcc}
\hline Rheological and drilling parameter & $\begin{array}{c}\text { Case 1 } \\
\text { Water }\end{array}$ & $\begin{array}{c}\text { Case 2 } \\
\text { Mud }\end{array}$ \\
\hline Fluid density $\left(\mathrm{kg} / \mathrm{m}^{3}\right)$ & 998.5 & 1006.3 \\
Cuttings density $\left(\mathrm{kg} / \mathrm{m}^{3}\right)$ & \multicolumn{2}{c}{2761.4} \\
Avg. cuttings size $(\mathrm{m})$ & \multicolumn{2}{c}{0.00201} \\
Flow behaviour index, $n$ & 1 & 0.51 \\
Viscosity consistency, $K,\left(\mathrm{~Pa} \mathrm{~s}^{n}\right)$ & 0.001 & 0.289 \\
Fluid velocity $(\mathrm{m} / \mathrm{s})$ & \multicolumn{2}{c}{$1.524-2.7432$} \\
Inner pipe rotation speed $(\mathrm{rpm})$ & \multicolumn{2}{c}{$0,80,120$} \\
Diameter ratio $\left(\kappa=D_{1} / D_{2}\right)$ & $0.64,0.70,0.80,0.90$ \\
Eccentricity $(e)$ & \multicolumn{2}{c}{0.623} \\
ROP $(\mathrm{m} / \mathrm{s})$ & \multicolumn{2}{c}{0.00508} \\
\hline
\end{tabular}

as higher fluid velocities will not improve on the amount of cuttings transport, but will also increase the annular pressure dramatically, which may adversely affect the formation pressure. A slight variation in cuttings concentration could however be observed in Figure 5(d) as fluid velocity increases from $1.524 \mathrm{~m} / \mathrm{s}$ to $2.749 \mathrm{~m} / \mathrm{s}$ for $\kappa=0.90$ when the carrier fluid is mud.

3.2. Effect of Diameter Ratio. Figure 6 presents the influence of diameter ratio on pressure loss and cuttings concentration at constant fluid velocity and $80 \mathrm{rpm}$. Analyses are shown for both water and mud as carrier fluids. For all cases, as diameter ratio increases from $\kappa=0.64$ to 0.90 , an increase in pressure loss also occurs, whereas a decrease in cuttings concentration is observed for each constant fluid velocity. This influence is however more pronounced for $\kappa=0.90$. As the annular gap becomes narrower, there are more interactions between cuttings-fluid and pipe walls which results in an increase in friction, and hence, pressure losses. It is worth noting that while the pressure loss difference between $\kappa=0.64$ and $\kappa=0.90$ could result in extreme increase by over $3600 \%$, a decrease of about $86 \%$ could be realised for cuttings concentration as water flows with a velocity of $1.524 \mathrm{~m} / \mathrm{s}$ (see Figures 6(a) and 6(b)). Moreover, in Figure 6(b), where the carrier fluid is water, there is almost no disparity in cuttings concentration when $\kappa=0.90$ for each constant fluid velocity. Although better cuttings transport could be observed in very 


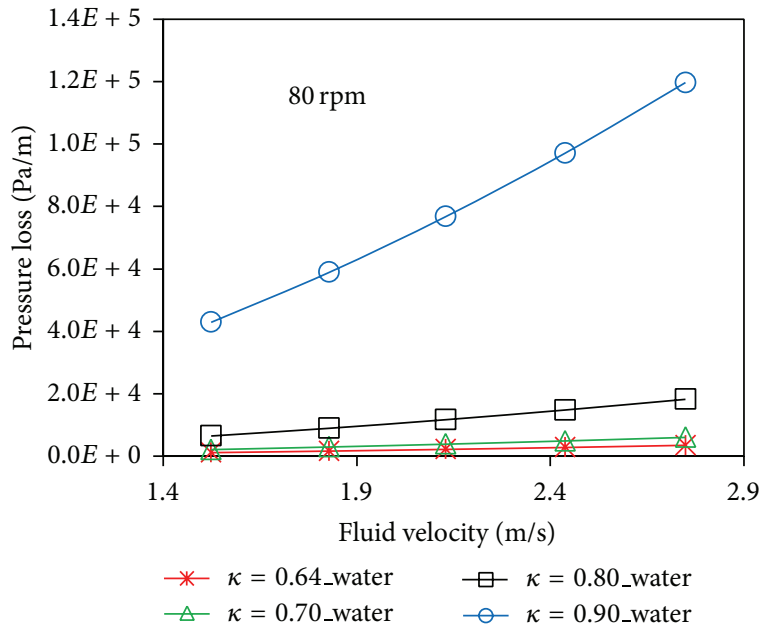

(a)

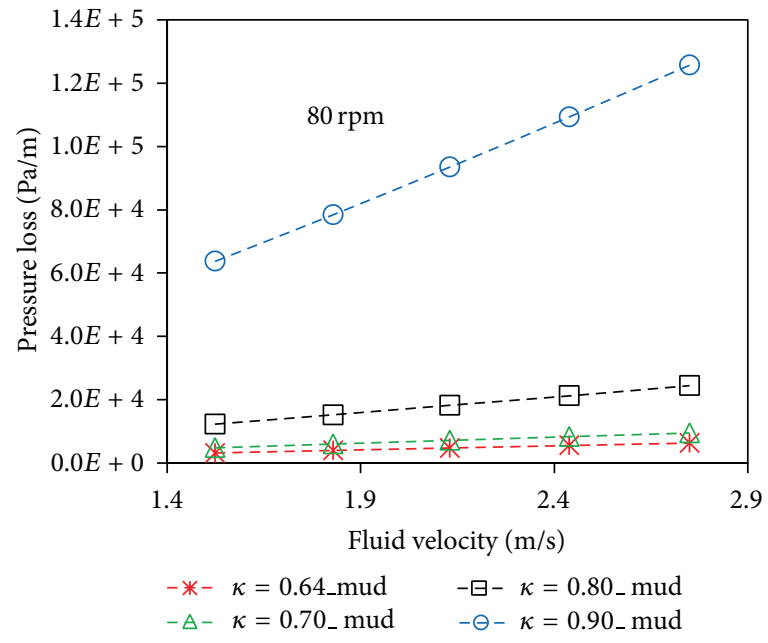

(c)

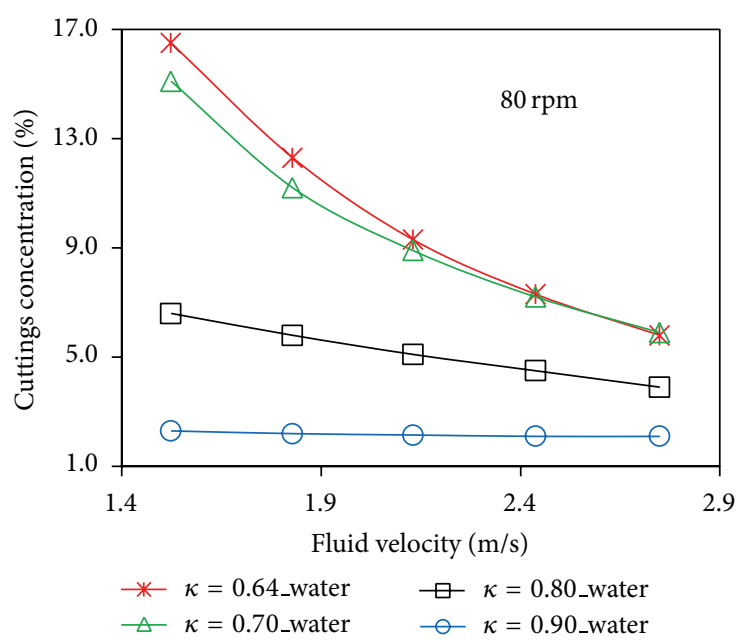

(b)

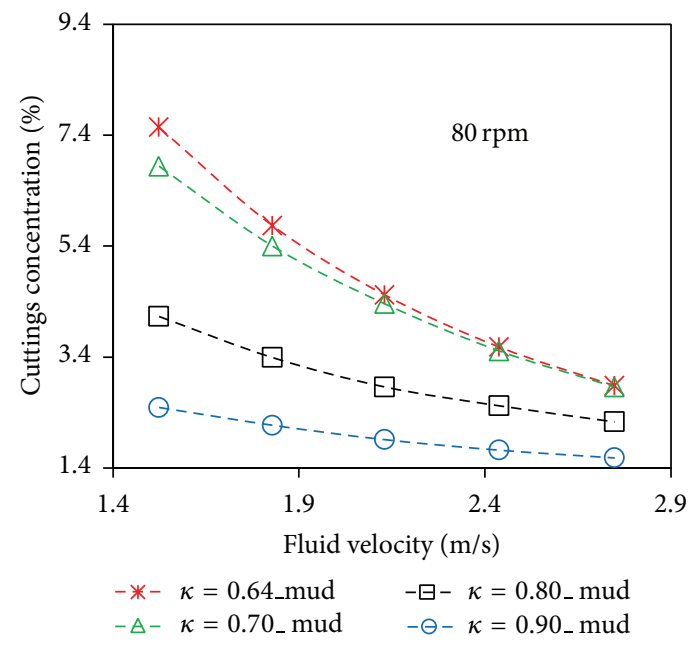

(d)

FIGURE 5: Effect of fluid velocity at constant diameter ratio on (a) pressure loss with water as carrier fluid, (b) cuttings concentration with water as carrier fluid, (c) pressure loss with mud as carrier fluid, (d) cuttings concentration with mud as carrier fluid.

narrow annuli, optimum drilling parameters must be selected to prevent excessive damage to the formation.

3.3. Effect of Drill Pipe Rotation. The effect of increasing drill pipe rotation on pressure loss and cuttings concentration is shown in Figure 7 when using both water and mud as carrier fluids. In Figures 7 (a) and 7(c), an increase in drill pipe rotation speed from $80 \mathrm{rpm}$ to $120 \mathrm{rpm}$ did not result in any significant increment in pressure losses with both water and mud as carrier fluids. The effect on cuttings concentration is quite predominant especially in annular gaps with diameter ratio below $\kappa=0.70$. For water as carrier fluid, as shown in Figure 7(b), the influence of increasing drill pipe rotation speed from $80 \mathrm{rpm}$ to $120 \mathrm{rpm}$ had a negative impact where the cuttings concentration increased when the diameter ratio is below $\kappa=0.70$. To explain this behaviour, the low viscous water would generate high turbulence as a function of both axial and rotational flows; which in addition to gravity could cause rapid settling of cuttings in the annulus. Above $\kappa=0.70$, the influence is virtually the same on cuttings concentration for each constant fluid velocity. On the contrary, when the carrier fluid is mud, as shown in Figure $7(\mathrm{~d})$, increasing drill pipe rotation speed from $80 \mathrm{rpm}$ to $120 \mathrm{rpm}$ shows a decrease in cuttings concentration for a diameter ratio range of $0.64 \leq \kappa<0.80$. Above $\kappa=0.80$, the influence is relatively negative on cuttings concentration. In all cases, the rotation effect is dominant at lower fluid velocities.

3.4. Effect of Fluid Type. The effect of Newtonian (water) and non-Newtonian Power-Law fluid (mud) on pressure loss and cuttings concentration are analysed in Figures 8(a) and 8 (b), respectively, at $120 \mathrm{rpm}$. With mud as carrier fluid, high pressure losses were recorded compared to water especially at low fluid velocity and $\kappa=0.90$ (see Figure $8(a)$ ). Similarly, the mud transported much cuttings compared to water especially 


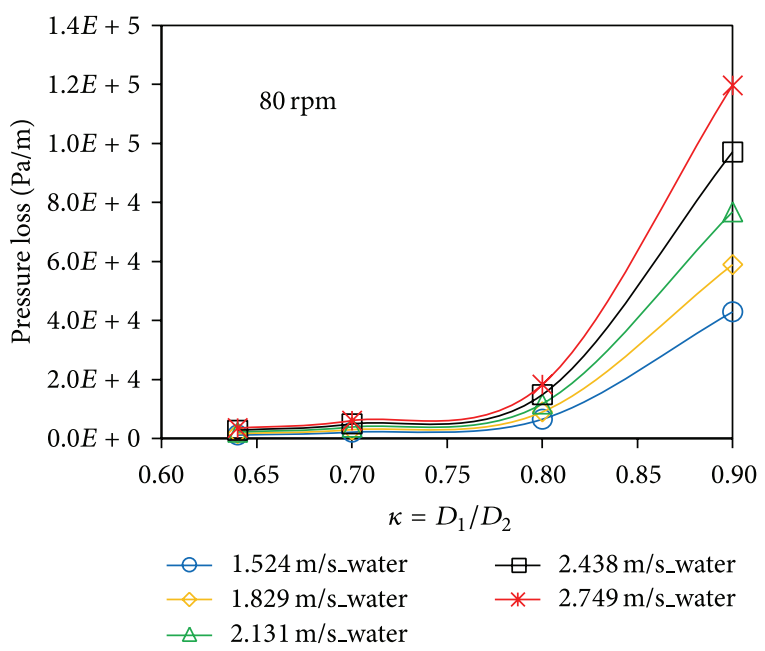

(a)

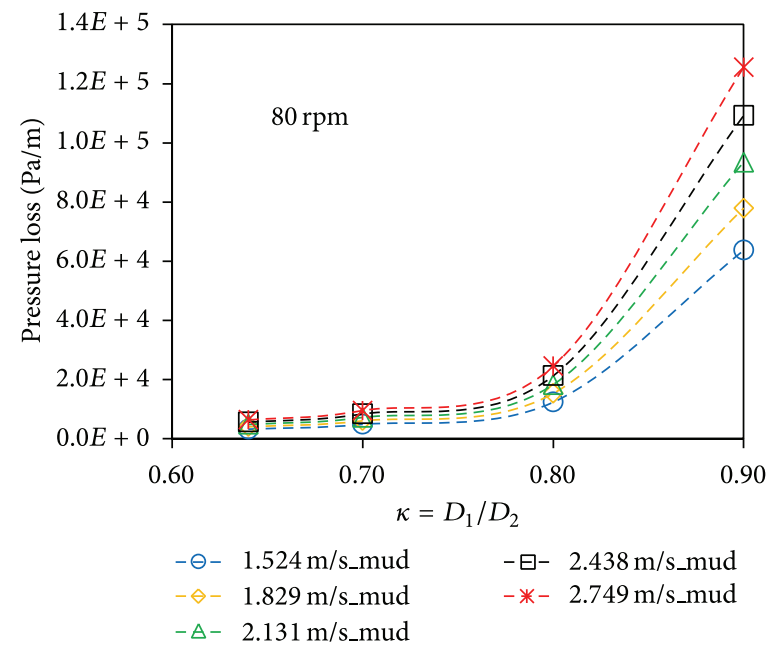

(c)

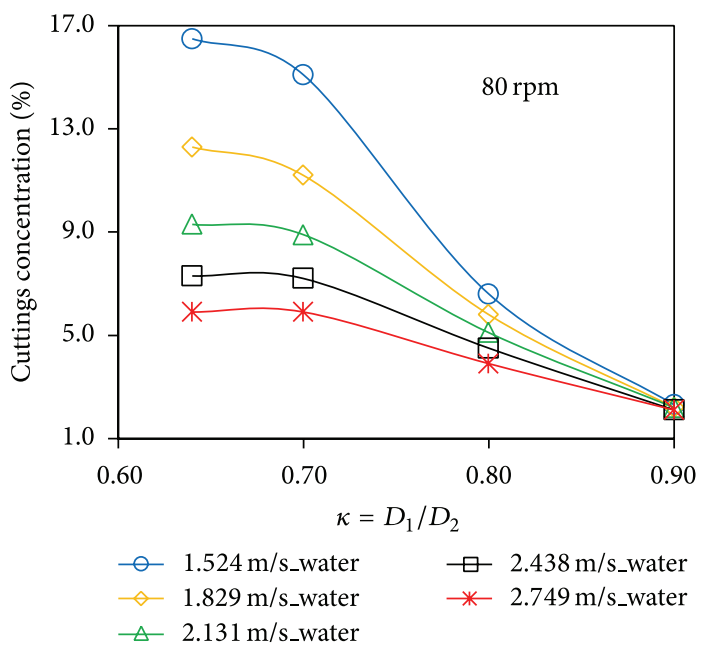

(b)



(d)

FIGURE 6: Effect of diameter ratio at constant fluid velocity on (a) pressure loss with water as carrier fluid, (b) cuttings concentration with water as carrier fluid, (c) pressure loss with mud as carrier fluid, (d) cuttings concentration with mud as carrier fluid.

at a constant diameter ratio of $\kappa=0.64$ and low fluid velocities (see Figure 8(b)). For example, $19.2 \%$ and $6.0 \%$ concentration of cuttings remained in the annulus after flowing with water and mud, respectively, for $\kappa=0.64$ and fluid velocity of $1.524 \mathrm{~m} / \mathrm{s}$. The performance of both fluids on cuttings concentration is quite similar at high diameter ratios.

3.5. Cuttings Volume Fraction, Velocity, and Profiles with Water as Carrier Fluid. Figures 9-11 show the contours of cuttings volume fraction, 3D streamlines of cuttings velocities, and radial measurements of cuttings velocity profiles, respectively, flowing with water at $1.524 \mathrm{~m} / \mathrm{s}$. As shown in Figure 9, the cuttings concentration accumulates in the narrowest gap of the eccentric annuli forming a bed due to gravity and the low viscosity of the carrier fluid. However, the rotation of the drill pipe from $0 \mathrm{rpm}$ to $120 \mathrm{rpm}$ reduces the cuttings bed by sweeping it into the widest gap where the fluid velocity is high to transport them to the surface. This observation is evident for all diameter ratios and shows the significance of drill pipe rotation in minimising differential pipe sticking, cuttings bed erosion, as well as excessive pressure losses. Figure 10 also depicts 3D streamlines of cuttings velocity. From the colour legend, the velocity of cuttings is high at some distance from the annular inlet and decreases to a minimum velocity towards the exit of the annular geometries. The decrease in cuttings velocity is an indication of cuttings settling to form a bed due to the low viscous nature of the carrier fluid and gravity. Drill pipe rotation induces a rotational flow on the cuttings bed into the annular mainstream and carries them to the surface. This rotation effect reduces the annular bed area for all diameter ratios. The radial measurements of cuttings velocity profiles at $1.524 \mathrm{~m} / \mathrm{s}$ and $120 \mathrm{rpm}$ are also presented in Figure 11. The radial distance is normalised. In the widest gap of the annular area, as shown in Figure 11(a), cuttings velocity increases with increasing diameter ratio where the peak velocities calculated are $1.896 \mathrm{~m} / \mathrm{s}, 1.970 \mathrm{~m} / \mathrm{s}, 2.043 \mathrm{~m} / \mathrm{s}$, and $1.999 \mathrm{~m} / \mathrm{s}$ for $\kappa=$ 


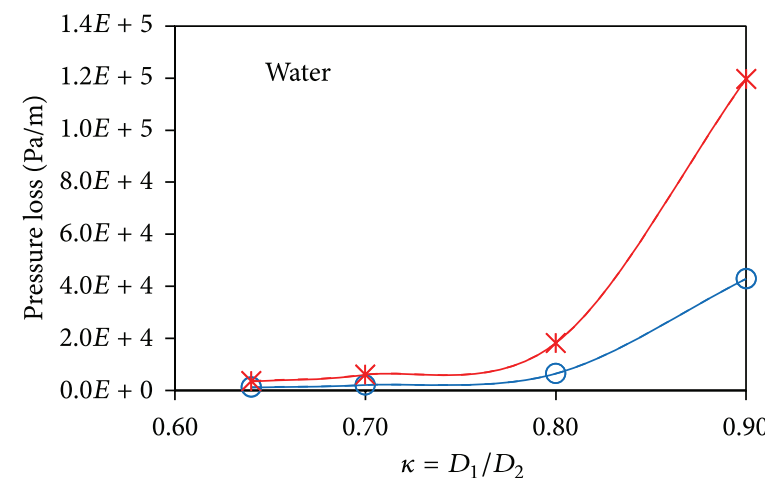

$\odot 1.524 \mathrm{~m} / \mathrm{s} \_80 \mathrm{rpm} \rightarrow 2.749 \mathrm{~m} / \mathrm{s} \_80 \mathrm{rpm}$

$-\ominus-1.524 \mathrm{~m} / \mathrm{s}_{-} 120 \mathrm{rpm} \quad-*-2.749 \mathrm{~m} / \mathrm{s}_{-} 120 \mathrm{rpm}$

(a)

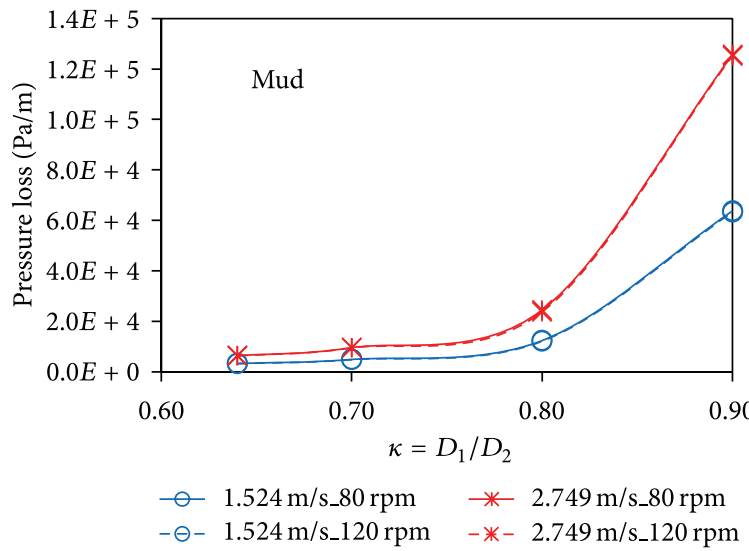

(c)

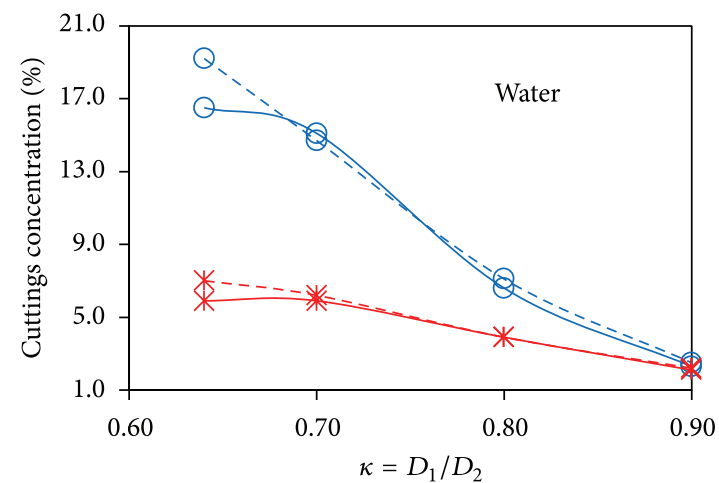

○ $1.524 \mathrm{~m} / \mathrm{s} \_80 \mathrm{rpm} \rightarrow 2.749 \mathrm{~m} / \mathrm{s} \_80 \mathrm{rpm}$ $-\ominus-1.524 \mathrm{~m} / \mathrm{s}_{-} 120 \mathrm{rpm} \quad-*-2.749 \mathrm{~m} / \mathrm{s} \_120 \mathrm{rpm}$

(b)

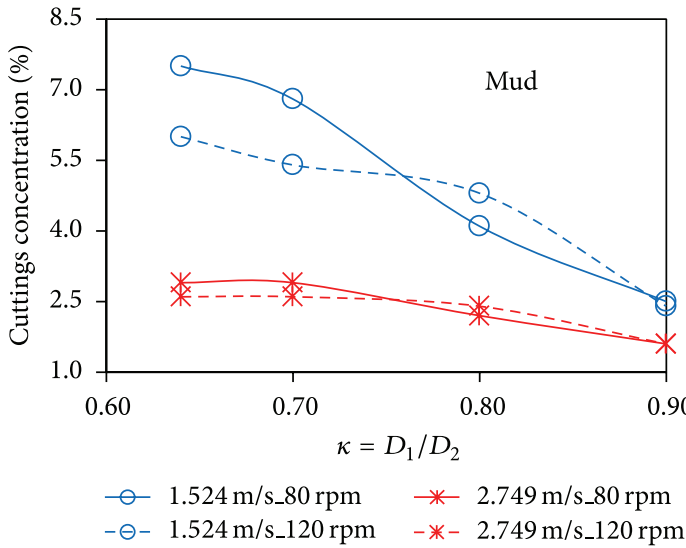

(d)

Figure 7: Effect of drill pipe rotation speed on (a) pressure loss with water as carrier fluid, (b) cuttings concentration with water as carrier fluid, (c) pressure loss with mud as carrier fluid, (d) cuttings concentration with mud as carrier fluid.

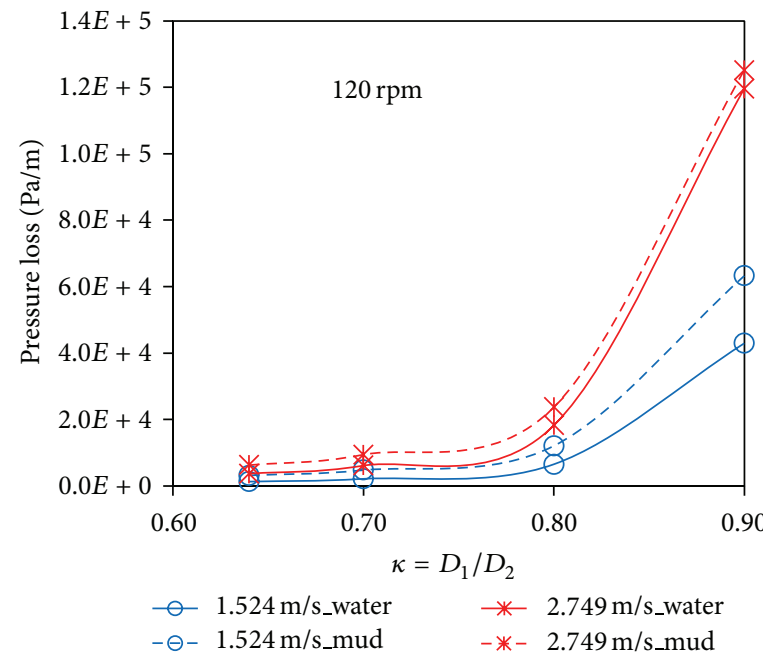

(a)

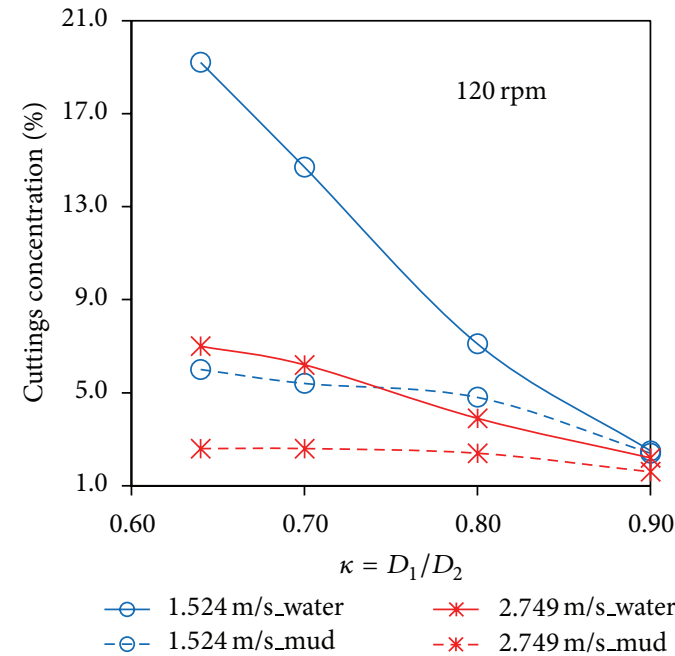

(b)

FIGURE 8: Effect of fluid type on (a) pressure loss and (b) cuttings concentration. 

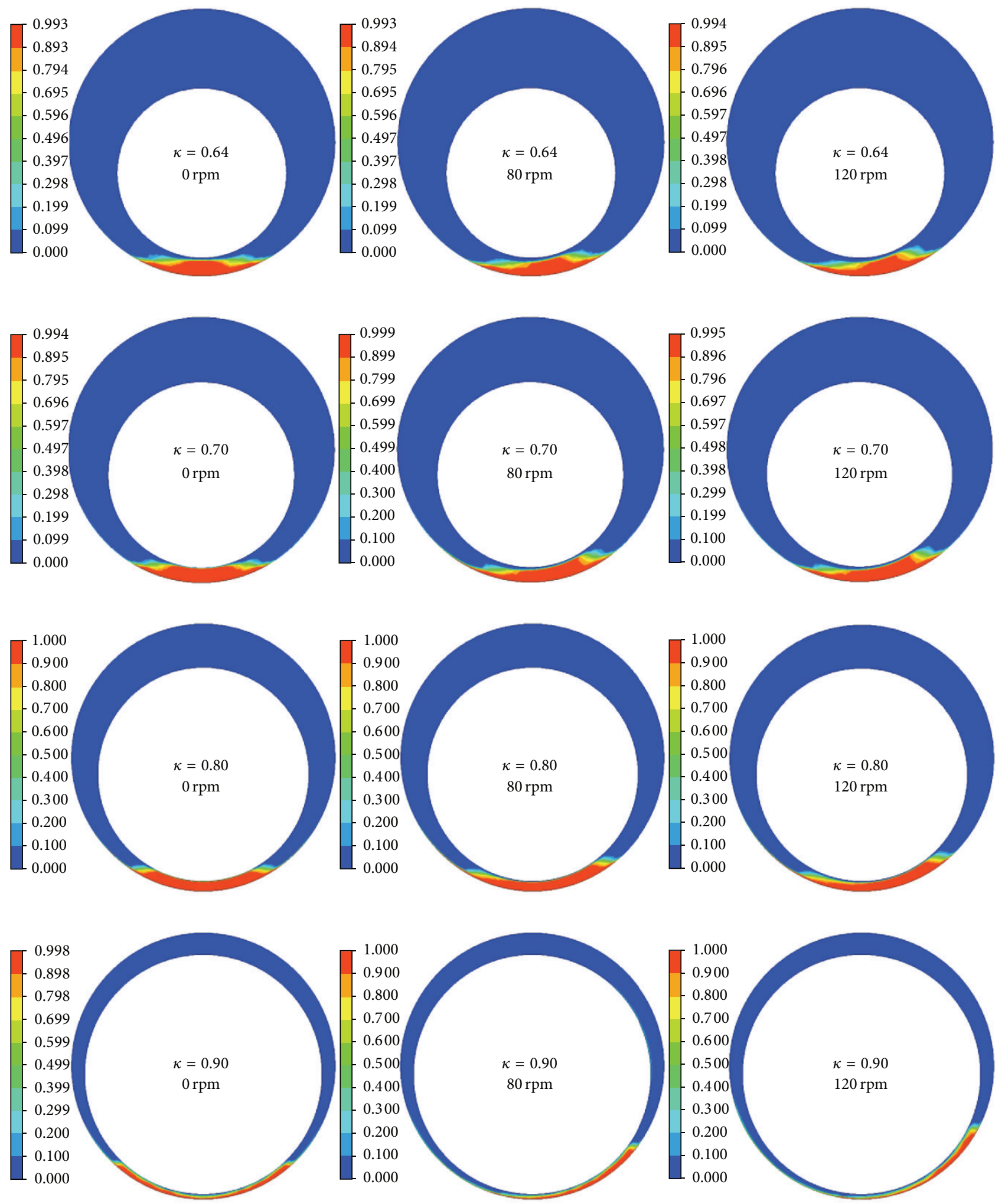

FIGURE 9: Contours of cuttings volume fraction for varying diameter ratios and inner pipe rotation with water as carrier fluid at $1.524 \mathrm{~m} / \mathrm{s}$. 


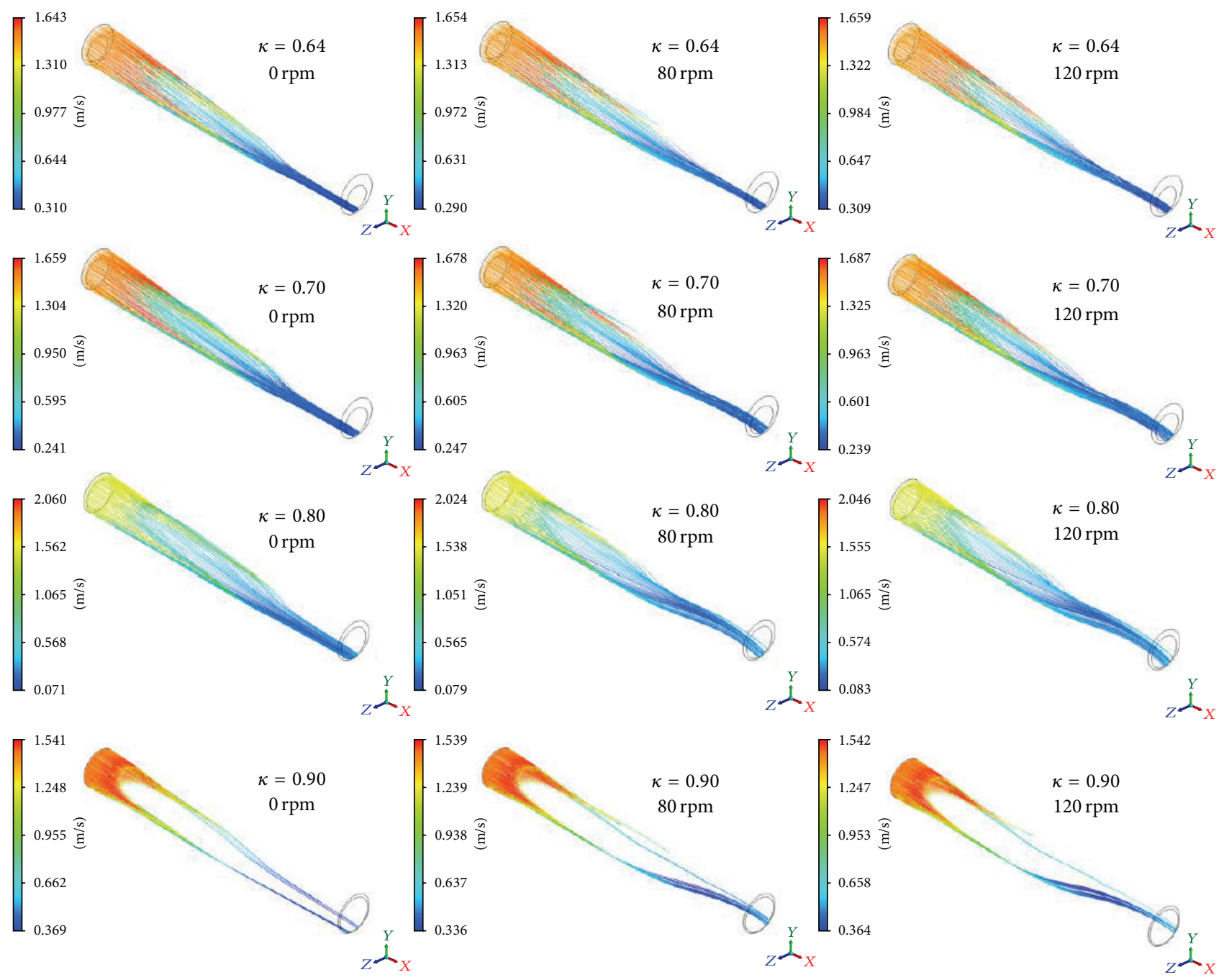

FIGURE 10: 3D streamlines of cuttings velocity for varying diameter ratios and inner pipe rotation with water as carrier fluid at $1.524 \mathrm{~m} / \mathrm{s}$.

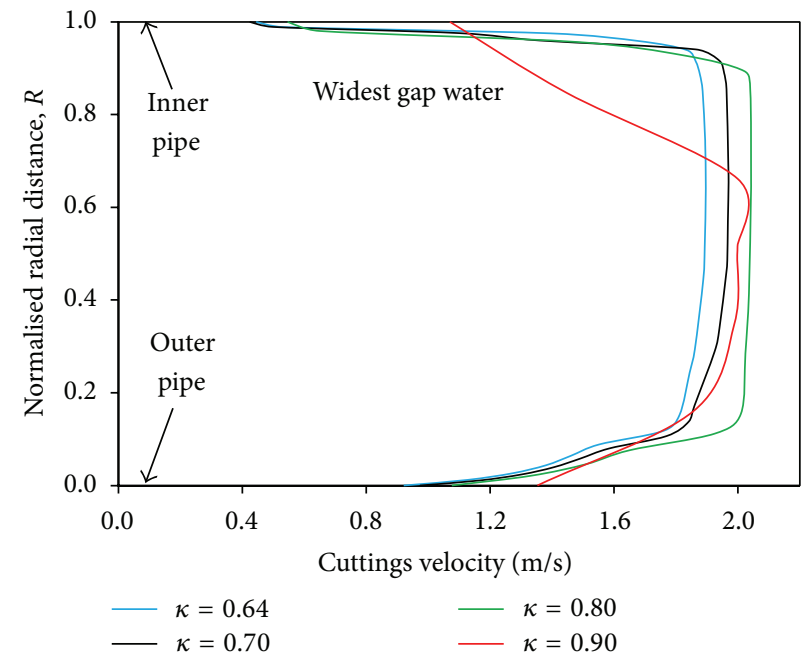

(a)

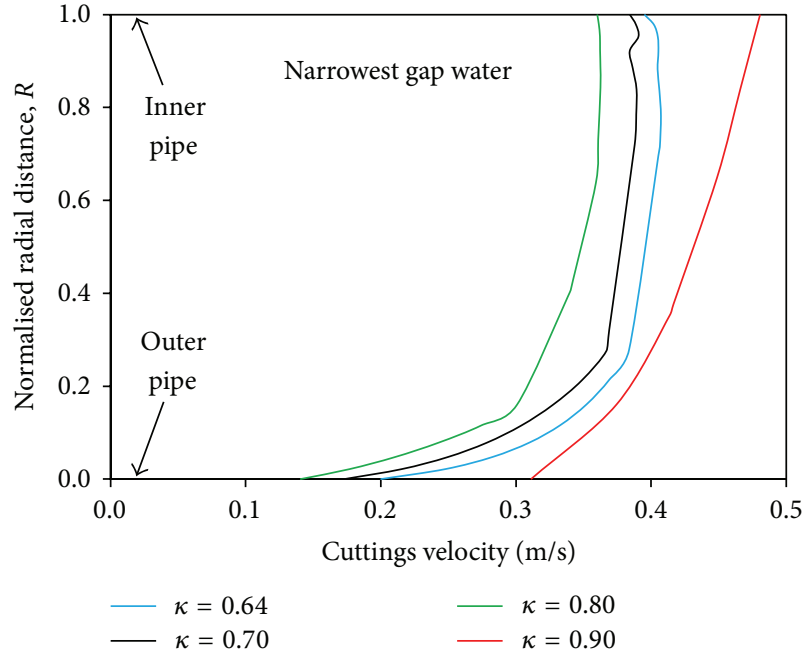

(b)

FIGURE 11: Cuttings velocity profiles with water as carrier fluid for varying diameter ratios at $1.524 \mathrm{~m} / \mathrm{s}$ and 120 rpm: (a) gap above inner pipe and (b) gap below inner pipe. 
$0.64,0.70,0.80$ and 0.90 , respectively. On the contrary, in Figure 11(b), the cuttings velocity in the narrowest annular gap show irregular profiles as diameter ratio increases. The effect of drill pipe rotation is seen to have greater impact on the cuttings velocity especially near the vicinity of the drill pipe where there is high shear. For example, at $\kappa=0.90$, the peak cuttings velocity recorded was $0.481 \mathrm{~m} / \mathrm{s}$, and it occurred at the vicinity of the drill pipe.

3.6. Cuttings Volume Fraction, Velocity, and Profiles with Mud as Carrier Fluid. With mud as carrier fluid and flowing at $1.524 \mathrm{~m} / \mathrm{s}$ and a drill pipe rotating at $120 \mathrm{rpm}$, Figure 12 shows a very small cuttings volume fraction within the annular gap. Due to the high viscous nature of the mud, many cuttings are able to be suspended in the mud and then transported to the surface. This reduces the cuttings tendency to slip to the bottom of the wellbore to form a bed. The cuttings velocity presented in 3D streamlines (see Figure 13) shows how the cuttings travel in almost the entire annular space for all diameter ratios. This indicates better carrying capacity of the mud in transporting the cuttings to the surface. The radial measurements of the cuttings velocity profiles as shown in Figure 14 further illustrate the mud's carrying capacity in both the widest and narrowest annular gaps. The peak cuttings velocity also increases with increasing diameter ratio and is recorded in the widest gap as $1.698 \mathrm{~m} / \mathrm{s}, 1.758 \mathrm{~m} / \mathrm{s}$, $1.838 \mathrm{~m} / \mathrm{s}$, and $1.840 \mathrm{~m} / \mathrm{s}$ for $\kappa=0.64,0.70,0.80$, and 0.90 , respectively, as shown in Figure 14(a). In the narrowest gap, as shown in Figure 14(b), the cuttings velocity profiles show irregular behaviours and are also very similar in magnitude for all diameter ratios. The peak cuttings velocities calculated are $1.000 \mathrm{~m} / \mathrm{s}, 1.304 \mathrm{~m} / \mathrm{s}, 1.025 \mathrm{~m} / \mathrm{s}$, and $1.071 \mathrm{~m} / \mathrm{s}$ for $\kappa=$ $0.64,0.70,0.80$, and 0.90, respectively (see Figure $14(\mathrm{~b})$ ).

\section{Conclusions}

The present study employs a CFD method to analyse the effects of fluid velocity, annular diameter ratio (ranging from 0.64 to 0.90 ), drill pipe rotation, and fluid type on the prediction of pressure losses and cuttings concentration for solid-fluid flow in eccentric horizontal annular geometries. The following can be inferred from this study.

(1) Using water as carrier fluid, simulation data for pressure loss and cuttings concentration are in good agreement with experimental data with mean percentage errors of $0.84 \%$ and $12 \%$, respectively. Similarly, with mud as carrier fluid, only $2.5 \%$ mean error exists between simulation and experimental pressure data, confirming the validity of the current model setup.

(2) Increasing annular fluid velocity significantly increases pressure losses, while a decrease in cuttings concentration occurs for each constant diameter ratio. This effect is however more pronounced for $\kappa=0.90$ when using both water and mud as carrier fluids. Annular pressure loss is dramatically increased by $97 \%$ while cuttings concentration is decreased by
$37 \%$ when the flowing mud velocity increased from $1.524 \mathrm{~m} / \mathrm{s}$ to $2.749 \mathrm{~m} / \mathrm{s}$ for $\kappa=0.90$.

(3) When other drilling parameters are kept constant, increasing diameter ratio increases pressure loss, whereas a decrease in cuttings concentration is observed for each constant fluid velocity. This influence is however pronounced for $\kappa=0.90$. Over $3600 \%$ increase in pressure loss could be realised while a decrease of about $86 \%$ in cuttings concentration is observed between diameter ratios of $\kappa=$ 0.64 and $\kappa=0.90$ for water flowing at a velocity of $1.524 \mathrm{~m} / \mathrm{s}$.

(4) Increasing drill pipe rotation speed from $80 \mathrm{rpm}$ to $120 \mathrm{rpm}$ did not result in any significant increment in pressure losses with both water and mud. The rotation effect on cuttings concentration is quite predominant especially in annular gaps with diameter ratio below $\kappa=0.70$ and at low fluid velocities. Contours of cuttings volume fraction show how rotation effect sweeps cuttings bed into the annular mainstream and transports them to the surface.

(5) Although mud recorded higher pressure losses compared to water, it has better carrying capacity as opposed to water especially at smaller diameter ratios. The performance of both fluids on cuttings concentration is quite similar at high diameter ratios.

\section{Nomenclature}

$A_{\text {bit }}:$ Area of bit $\left(\mathrm{m}^{2}\right)$

$C_{D}$ : Drag coefficient (-)

$C_{\mathrm{cf}}$ : Cuttings feed concentration (-)

$C_{\mathrm{cT}}$ : Total cuttings concentration (-)

$C_{\alpha}$ : Volume fraction of phase $\alpha$

$C_{\varepsilon 1}:(k-\varepsilon)$ turbulence model constant (1.44)

$C_{\varepsilon 2}: \quad(k-\varepsilon)$ turbulence model constant (1.92)

$C_{\mu}: \quad(k-\varepsilon)$ turbulence model constant (0.09)

$d_{s}: \quad$ Solid particle mean diameter $(\mathrm{m})$

$D_{1}$ : Outer diameter of inner pipe (m)

$D_{2}$ : Inner diameter of outer pipe $(\mathrm{m})$

$D_{h}$ : Hydraulic diameter, $D_{2}-D_{1}(\mathrm{~m})$

$e: \quad$ Eccentricity $\left(2 \delta /\left(D_{2}-D_{1}\right)\right)$

$g: \quad$ Gravity vector $\left(\mathrm{m} / \mathrm{s}_{2}\right)$

$h_{l}$ : Fluid phase volume fraction (-)

$h_{s}$ : Solid phase volume fraction $(-)$

$K: \quad$ Consistency index $\left(\mathrm{Pa} \cdot \mathrm{s}^{n}\right)$

$k_{\alpha}$ : Turbulence kinetic energy $\left(\mathrm{m}_{2} / \mathrm{s}_{2}\right)$

$L: \quad$ Annular geometry length (m)

$L_{h}: \quad$ Hydrodynamic length (m)

$\dot{m}$ : Mass flow rate $(\mathrm{kg} / \mathrm{s})$

$M: \quad$ Interphase momentum transfer

$M_{d}$ : Drag force per unit volume $\left(\mathrm{N} / \mathrm{m}_{3}\right)$

$M_{L}$ : Lift force per unit volume $\left(\mathrm{N} / \mathrm{m}_{3}\right)$

$n$ : $\quad$ Flow behaviour index $(-)$

$N_{\mathrm{Re}}$ : Fluid Reynolds number (-)

$N_{\mathrm{Re}_{p}}$ : Solid particles Reynolds number (-)

$N_{\mathrm{Re}_{\omega}}$ : Vorticity Reynolds number (-) 

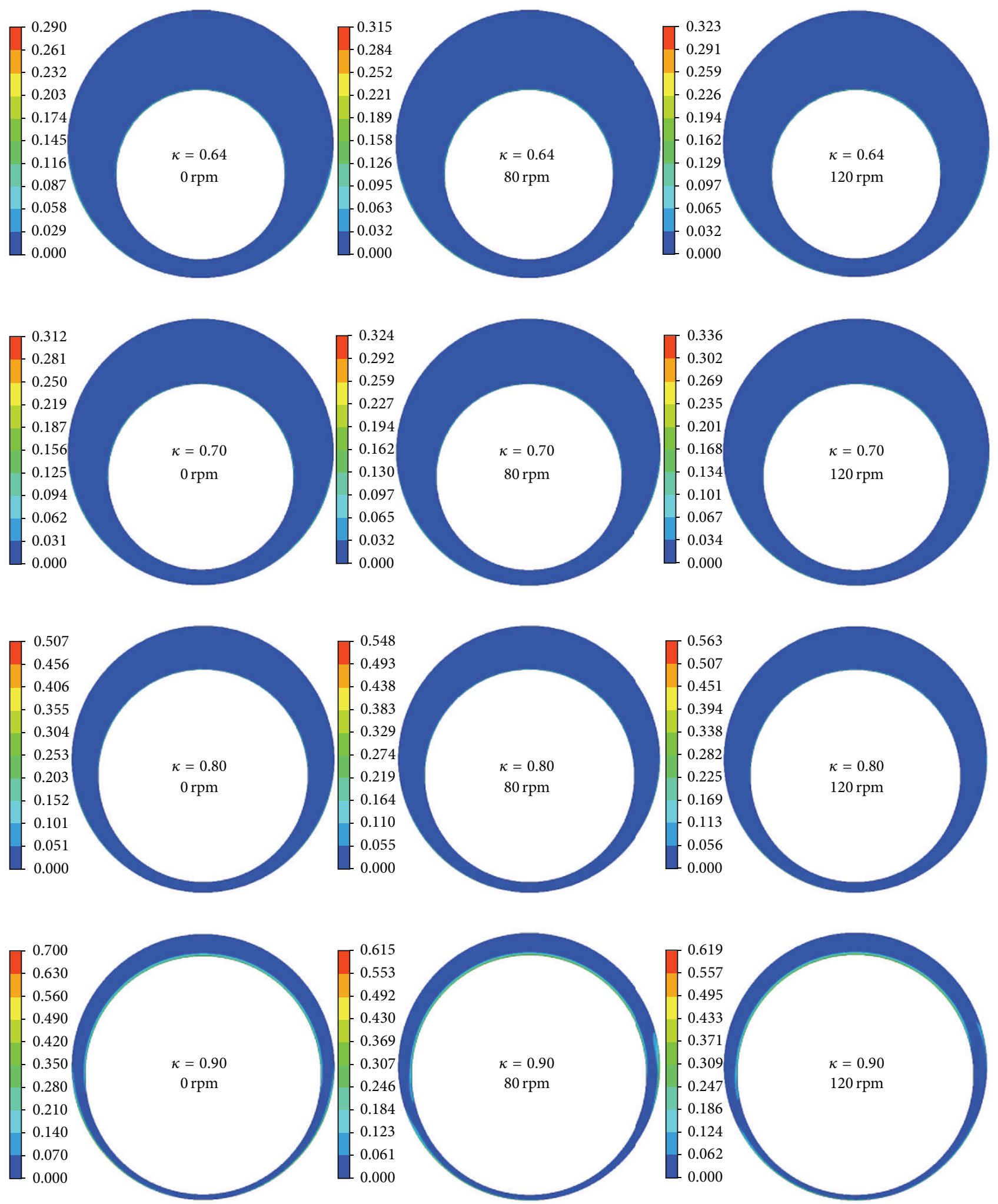

FIGURE 12: Contours of cuttings volume fraction for varying diameter ratios and inner pipe rotation with mud as carrier fluid at $1.524 \mathrm{~m} / \mathrm{s}$. 




FIGURE 13: 3D streamlines of cuttings velocity for varying diameter ratios and inner pipe rotation with mud as carrier fluid at $1.524 \mathrm{~m} / \mathrm{s}$.

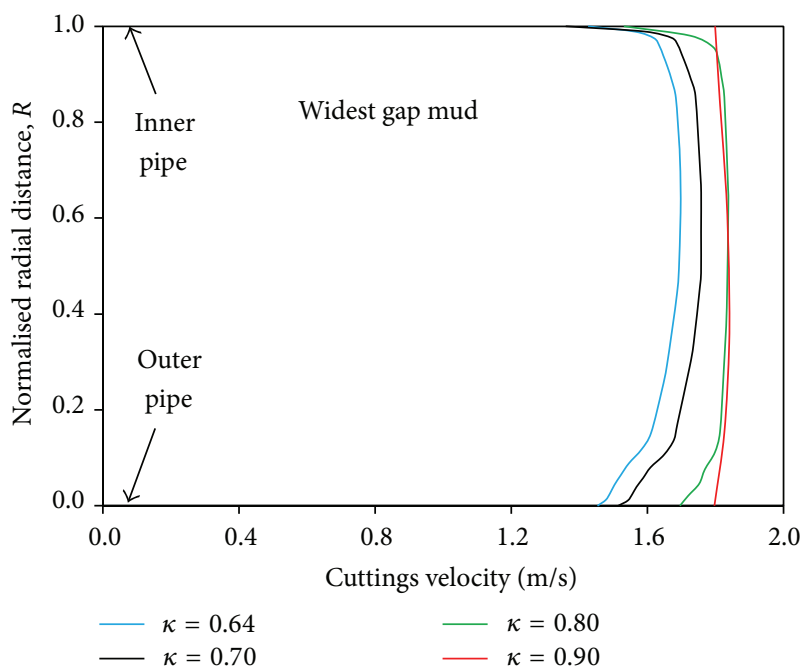

(a)

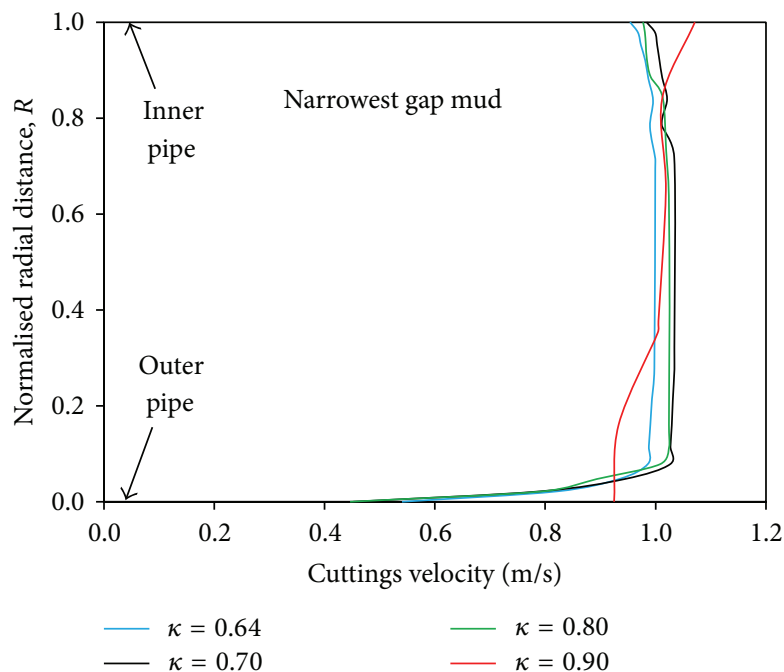

(b)

Figure 14: Cuttings velocity profiles with mud as carrier fluid for varying diameter ratio at $1.524 \mathrm{~m} / \mathrm{s}$ and 120 rpm: (a) gap above inner pipe and (b) gap below inner pipe. 
$P_{\alpha}: \quad$ Phase pressure $(\mathrm{Pa})$

$P_{s}: \quad$ Solid particle pressure $(\mathrm{Pa})$

$Q: \quad$ Volumetric flow rate $\left(\mathrm{m}^{3} / \mathrm{s}\right)$

$r$ : $\quad$ Radial distance $(\mathrm{m})$

$R: \quad$ Normalised radial distance $\left(\left(R_{2}-r\right) /\left(R_{2}-R_{1}\right)\right)$

$R_{1}$ : Outer radius of inner pipe (m)

$R_{2}$ : Inner radius of outer pipe (m)

ROP: Rate of penetration $(\mathrm{m} / \mathrm{s})$

$R_{T}: \quad$ Transport ratio (-)

$T_{\alpha \beta}^{(\varepsilon)}$ : Interphase transfer for $\mathcal{\varepsilon}$

$T_{\alpha \beta}^{(k)}$ : Interphase transfer for $k$

$U_{\alpha}:$ Phase velocity vector $(\mathrm{m} / \mathrm{s})$

$U_{l}: \quad$ Fluid phase velocity vector $(\mathrm{m} / \mathrm{s})$

$U_{s}$ : Solid phase velocity vector $(\mathrm{m} / \mathrm{s})$.

\section{Symbols}

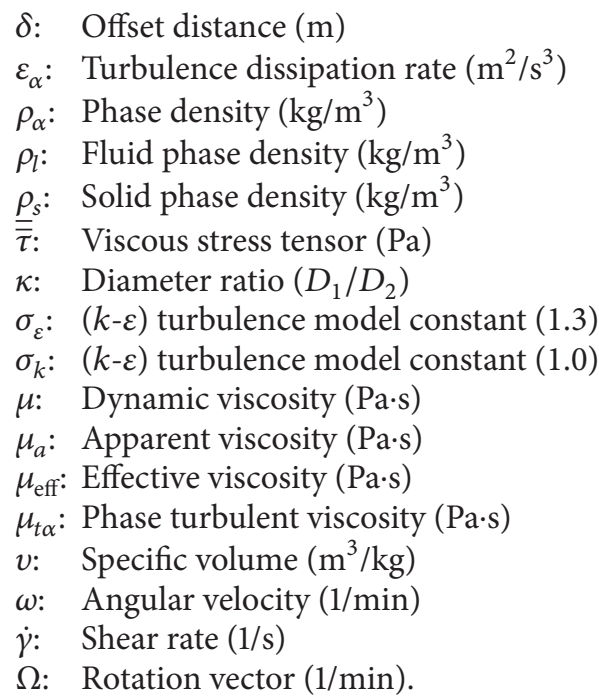

\section{Unit Conversion Factors}

$$
\begin{array}{ll}
\mathrm{ft} \times 0.3048: & E+00=\mathrm{m} \\
\text { inch } \times 25.4: & E-03=\mathrm{m} \\
\mathrm{Gal}(\mathrm{US}) \times 3.785: & E+00=\text { liter } \\
\mathrm{gal} / \mathrm{min}(\mathrm{gpm}) \times 6.309: & E-05=\mathrm{m}^{3} / \mathrm{s} \\
\mathrm{psi} \times 6.8948: & E-03=\mathrm{MPa} \\
\mathrm{ppg} \times 1.198: & E+02=\mathrm{kg} / \mathrm{m}^{3} .
\end{array}
$$

\section{Conflict of Interests}

The authors declare that there is no conflict of interests regarding the publication of this paper.

\section{References}

[1] P. H. Tomren, A. W. Iyoho, and J. J. Azar, "Experimental study of cuttings transport in directional wells," SPE Drilling Engineering, vol. 1, no. 1, pp. 43-56, 1986.

[2] T. E. Becker and J. J. Azar, Mud-Weight and Hole-Geometry Effects on Cuttings Transport While Drilling Directionally, Society of Petroleum Engineers, SPE-14711-MS, 1985.
[3] R. B. Adari, S. Miska, E. Kuru, P. Bern, and A. Saasen, "Selecting drilling fluid properties and flow rates for effective hole cleaning in high-angle and horizontal wells," in Proceedings of the SPE Annual Technical Conference and Exhibition, paper SPE-63050MS, pp. 273-281, Dallas, Tex, USA, October 2000.

[4] T. R. Sifferman and T. E. Becker, "Hole cleaning in full-scale inclined wellbores," SPE Drilling Engineering, vol. 7, no. 2, pp. 115-120, 1992.

[5] R. Ahmed, M. Sagheer, N. Takach et al., "Experimental studies on the effect of mechanical cleaning devices on annular cuttings concentration and applications for optimizing ERD systems," in Proceedings of the SPE Annual Technical Conference and Exhibition, paper SPE-134269-MS, pp. 2016-2028, Florence, Italy, September 2010.

[6] M. E. Ozbayoglu, A. Saasen, M. Sorgun, and K. Svanes, "Critical fluid velocities for removing cuttings bed inside horizontal and deviated wells," Petroleum Science and Technology, vol. 28, no. 6, pp. 594-602, 2010.

[7] J. O. Ogunrinde and A. Dosunmu, "Hydraulic optimization for efficient hole cleaning in deviated and horizontal wells," in Proceedings of the SPE Nigerian Annual Technical Conference and Exhibition, paper SPE 162970, Abuja, Nigeria, August 2012.

[8] M. E. Ozbayoglu and M. Sorgun, "Frictional pressure loss estimation of water-based drilling fluids at horizontal and inclined drilling with pipe rotation and presence of cuttings," in Proceedings of the SPE Oil and Gas India Conference and Exhibition, paper SPE-127300-MS, Mumbai, India, January 2010.

[9] M. Sorgun, I. Aydin, and M. E. Ozbayoglu, "Friction factors for hydraulic calculations considering presence of cuttings and pipe rotation in horizontal/highly-inclined wellbores," Journal of Petroleum Science and Engineering, vol. 78, no. 2, pp. 407-414, 2011.

[10] O. M. Evren, E. Reza O, O. A. Murat, and Y. Ertan, "Estimation of "very-difficult-to-identify" data for hole cleaning, cuttings transport and pressure drop estimation in directional and horizontal drilling," in Proceedings of the IADC/SPE Asia Pacific Drilling Technology Conference and Exhibition, paper SPE-136304-MS, pp. 668-685, Ho Chi Minh City, Vietnam, November 2010.

[11] N. C. G. Markatos, R. Sala, and D. R. Spalding, "Flow in an annulus of non-uniform gap," Transactions of the Institution of Chemical Engineers, vol. 56, no. 1, pp. 28-35, 1978.

[12] S.-M. Han, Y.-K. Hwang, N.-S. Woo, and Y.-J. Kim, "Solidliquid hydrodynamics in a slim hole drilling annulus," Journal of Petroleum Science and Engineering, vol. 70, no. 3-4, pp. 308-319, 2010.

[13] M. Mokhtari, M. Ermila, A. N. Tutuncu, and M. Karimi, "Computational modelling of drilling fluids dynamics in casing drilling," in Proceedings of the SPE Eastern Regional Meeting, paper SPE-161301-MS, Lexington, Ky, USA, October 2012.

[14] T. N. Ofei, S. Irawan, and W. Pao, "Modelling ofpressure drop in eccentric narrow horizontal annuli with the presence of cuttings and rotating drillpipe," International Journal of Oil, Gas and Coal Technology. In press.

[15] G. M. Faeth, "Mixing, transport and combustion in sprays," Progress in Energy and Combustion Science, vol. 13, no. 4, pp. 293-345, 1987. 
[16] M. Eesa and M. Barigou, "Horizontal laminar flow of coarse nearly-neutrally buoyant particles in non-Newtonian conveying fluids: CFD and PEPT experiments compared," International Journal of Multiphase Flow, vol. 34, no. 11, pp. 997-1007, 2008.

[17] B. G. M. van Wachem and A. E. Almstedt, "Methods for multiphase computational fluid dynamics," Chemical Engineering Journal, vol. 96, no. 1-3, pp. 81-98, 2003.

[18] C. Y. Wen and Y. H. Yu, "Mechanics of fluidization," Chemical Engineering Progress Symposium Series, vol. 62, pp. 100-111, 1966.

[19] D. Gidaspow, Multiphase Flow and Fluidization, Academic Press, 1994.

[20] P. G. Saffman, "The lift on a small sphere in a slow shear flow," Journal of Fluid Mechanics, vol. 22, no. 2, pp. 385-400, 1965.

[21] P. G. Saffman, "The lift on a small sphere in a slow shear flowcorrigendum," Journal of Fluid Mechanics, vol. 31, no. 3, p. 624, 1968.

[22] R. Mei and J. F. Klausner, "Shear lift force on spherical bubbles," International Journal of Heat and Fluid Flow, vol. 15, no. 1, pp. 62-65, 1994.

[23] B. E. Launder and D. B. Spalding, "The numerical computation of turbulent flows," Computer Methods in Applied Mechanics and Engineering, vol. 3, no. 2, pp. 269-289, 1974.

[24] C. A. Shook and M. C. Roco, Slurry Flow: Principles and Practice, Butterworth-Heimemann, London, UK, 1991.

[25] R. E. Osgouei, Determination of cuttings transport properties of gasified drilling fluids [Ph.D. thesis], Middle East Technical University, Ankara, Turkey, 2010.

[26] S. V. Patankar, Numerical Heat Transfer and Fluid Flow, Hemisphere Publishing Corp., 1980. 

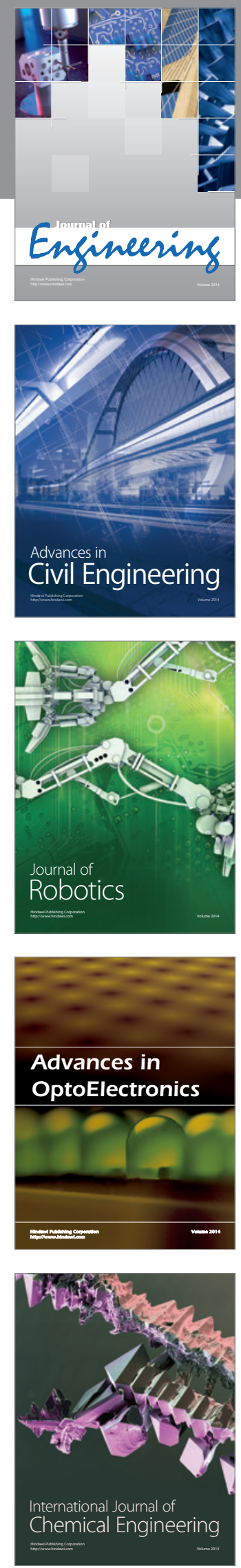

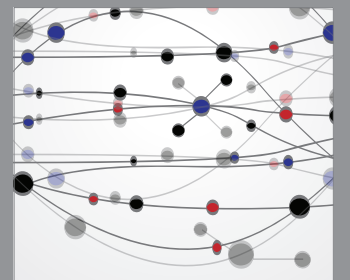

The Scientific World Journal
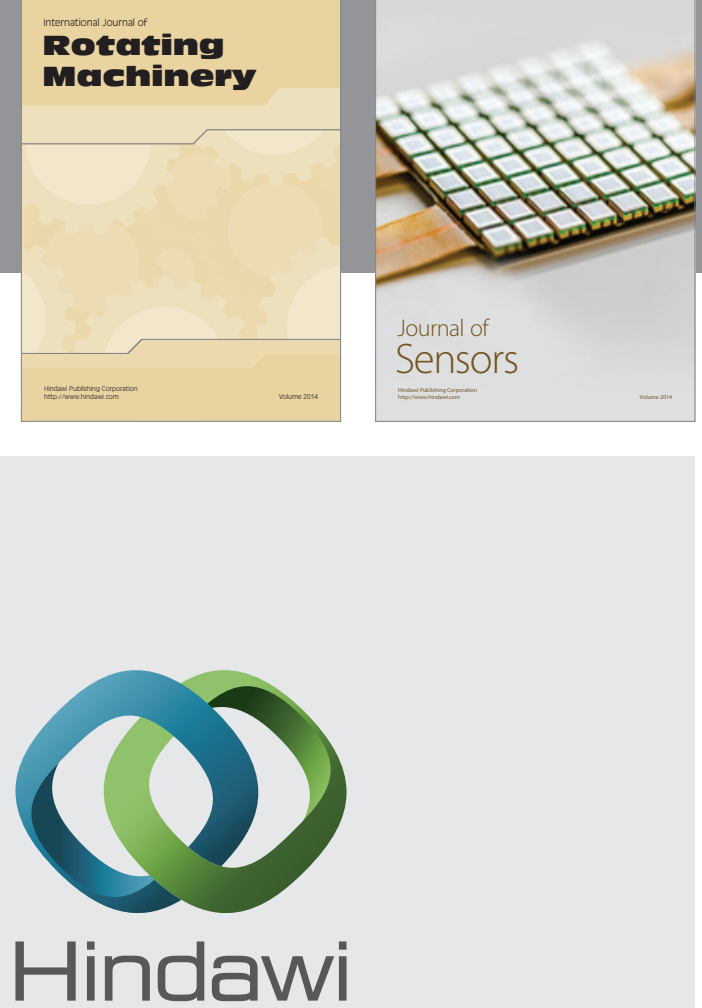

Submit your manuscripts at http://www.hindawi.com
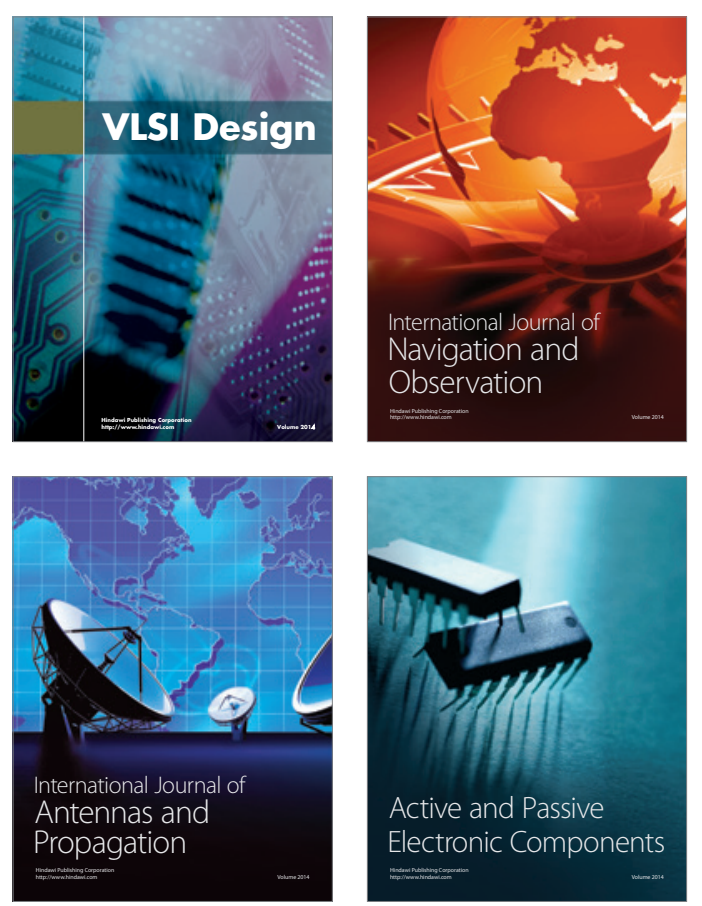
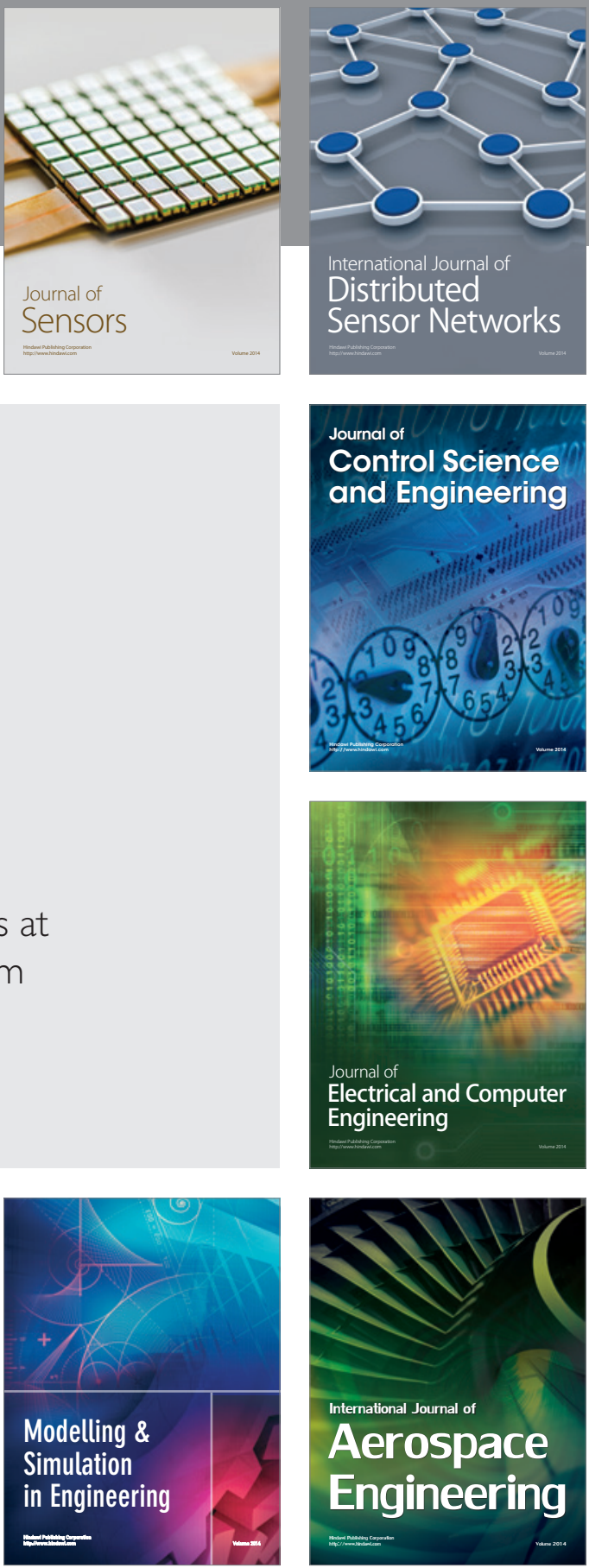

Journal of

Control Science

and Engineering
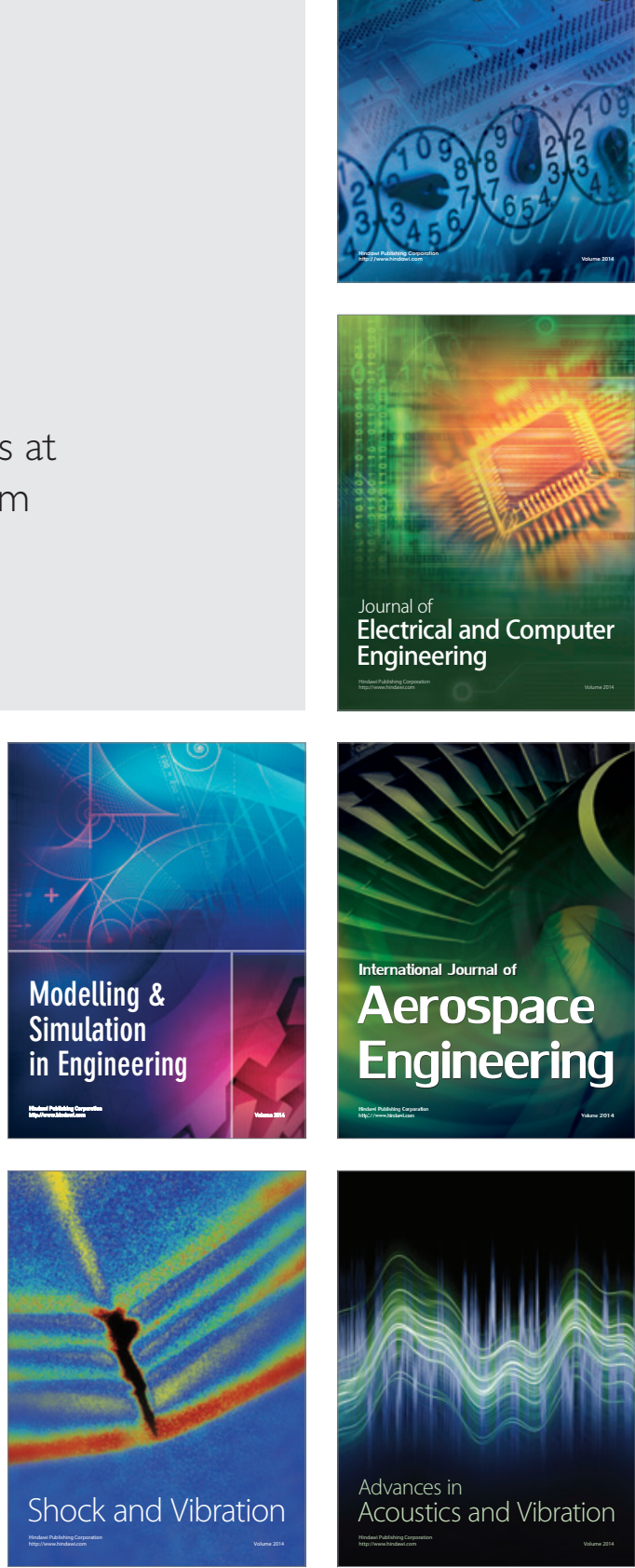